\title{
Some Revenge Now or More Revenge Later? Applying an Intertemporal Framework to Retaliatory Aggression
}

\author{
Samuel J. West ${ }^{1 *}$, Emily N. Lasko ${ }^{1}$, Calvin J. Hall ${ }^{2}$, Nayaab G. Khan ${ }^{2}$, David S. Chester ${ }^{2}$ \\ ${ }^{1}$ Department of Surgery, Virginia Commonwealth University, USA \\ ${ }^{2}$ Department of Psychology, Virginia Commonwealth University, USA \\ In press at Motivation Science
}

Word Count: 10,305

Abstract Word Count: 179

*Correspondence should be addressed to:

Samuel J. West

Department of Surgery

Virginia Commonwealth University

Richmond, VA 23284, USA

$1-804-828-6691$

westsj3@vcu.edu

Open Science Statement: Our preregistered hypotheses and study protocol(s) are publicly available (https://osf.io/46pg7/wiki/), along with all de-identified data and code needed to reproduce our findings (https://osf.io/46pg7/files/). 


\begin{abstract}
Retaliatory aggression is a rewarding behavior. Decisions about rewarding behaviors often involve an intertemporal bias, such that people prefer immediate rewards and discount delayed rewards. We integrated these literatures to test whether the delay discounting framework could be applied to retaliatory aggression. Across six studies (total $N=1,508$ ), participants repeatedly chose between immediate-but-lesser or delayed-but-greater retaliation. As with other rewards (e.g., money), participants preferred immediate-but-lesser retaliation, discounting the value of delayed-but-greater revenge. Rates of aggression discounting were temporally stable and associated with greater aggressive behavior. Experimentally-induced angry rumination reduced discounting rates, motivating participants to wait longer to inflict greater harm. Participants with greater antagonistic traits (e.g., physical sadism), displayed stronger preferences for delayed-butgreater vengeance. These findings suggest that some dispositionally aggressive individuals may delay retaliation in service of greater future revenge. Our results bolster the important role of reward in retaliatory aggression and suggest that an intertemporal framework is likely a fruitful area of investigation for antisocial behavior. We discuss the implications of our findings in relation to contemporary theories of aggression and broader theories of antisocial behavior.
\end{abstract}

Keywords: aggression, delay discounting, intertemporal choice, revenge, provocation 


\section{Introduction}

Retaliatory aggression, more commonly known as revenge or vengeance ${ }^{1}$, refers to any attempt to intentionally harm a perceived source of provocation (Bushman, Baumeister, \& Phillips, 2001). Much research has focused on the proximate and ultimate forces that shape retaliatory aggression (Anderson \& Bushman, 2002; McCullough, Kurzban, \& Tabak, 2013). Yet this literature has largely neglected an important aspect of revenge-seeking — the timeframe in which retaliatory aggression is exacted. In what follows, we drew from the established literature on delay discounting to develop two measures of preference for immediate-but-lesser versus delayed-but-greater retaliatory aggression. We examined these preferences across six studies, alongside the situational and dispositional forces that influence them.

\section{Intertemporal Choice}

Intertemporal choice broadly refers to decisions that are made between different options that occur over varying timeframes (Green \& Myerson, 2004). The context most frequently examined in this literature is that of potential rewards (e.g., money; Green, Fry, \& Myerson, 1994). This literature has revealed some peculiar human decision-making tendencies. For instance, people often prefer immediate-but-lesser rewards (e.g., \$1 now) over delayed-butgreater rewards (e.g., \$5 in one week). This preference for immediate rewards is most often explained by a psychological phenomenon known as delay discounting — in which individuals discount the value of a reward as it becomes more distant in time (Green \& Myerson, 2004). Delay discounting is an ingrained aspect of our evolved psychology, as it has been demonstrated in both humans and non-human mammals (e.g., Peck \& Byrne, 2019), is instantiated in evolutionarily-conserved neural circuitry (Frost \& McNaughton, 2017), and is geneticallyheritable (Anokhin, Grant, Mulligan, \& Heath, 2015). Such intertemporal preferences are consequential, as they are implicated in a host of costly human tendencies. Such preferences for

${ }^{1}$ The current work uses the terms retaliatory aggression, revenge, retaliation, and vengeance interchangeably. 
immediate rewards during intertemporal choice are robustly linked to addictive behaviors (e.g., Kirby, Petry, \& Bickel, 1999), poor academic performance (Kirby, Winston, \& Santiesteban, 2005) and greater externalizing psychopathology (e.g., attention deficit and hyperactivity disorder; Barkley, Edwards, Laneri, Fletcher, \& Metevia, 2001). Across these domains, intertemporal choice preferences are costly at a grand scale.

\section{Delay Discounting and Aggression}

One form of externalizing behavior that is particularly relevant to this investigation is aggression. Individuals' proclivity for aggressive acts is linked to preferences for immediate rewards (e.g., Koepfler, Brewster, Stoloff, \& Saville, 2012). Among adolescents, a preference for immediate rewards is linked to symptoms of conduct disorder (White et al., 2014). Rates of delay discounting are also positively associated with aggressive behavior in police officers (Koepfler et al., 2012), parolees (Cherek, Moeller, Dougherty, \& Rhoades, 1997), and participants with borderline personality disorder (Dougherty, Bjork, Huckabee, Moeller, \& Swann, 1999). Yet why would such a preference for immediate rewards impact aggression?

\section{Aggression as a Rewarding Behavior}

Although aggression is often characterized as arising from aversive states such as pain and frustration, a growing body of literature indicates that aggressive acts themselves are rewarding (i.e., the revenge-as-reward effect; Chester, 2017). This paradigm shift holds mostly for retaliatory forms of aggression. Retaliatory aggression is associated with increased activity in brain regions associated with the subjective experience of reward (e.g., nucleus accumbens;

Chester \& DeWall, 2016; Chester, Lynam, Milich, \& DeWall, 2018). Aggression is also linked to altered brain structures that regulate the experience of reward (e.g., ventromedial prefrontal cortex; Chester, Lynam, Milich, \& DeWall, 2017). Evolutionary accounts of revenge indicate 
that transgressions evoke an emotional need to obtain revenge, and that such needs can be observed among humans, bonobos, and chimpanzees alike (Boehm, 2011). In laboratory settings, people report and exhibit motivation to retaliate because they anticipate that it will improve bad moods evoked by provocation or perceptions of injustice (Bushman, 2002; Bushman et al., 2001; Chester \& DeWall, 2017; Gollwitzer \& Bushman, 2012). Further, a growing body of literature examining appetitive aggression indicates that the intrinsic enjoyment of violence is a crucial factor in more severe forms of violence (e.g., Elbert, Schauer, \& Moran, 2018). Taken together, there is a diverse array of evidence that the rewarding nature of aggression drives people to retaliate. Yet little psychological literature has examined the intertemporal dynamics of retaliation.

Given that retaliatory aggression is a rewarding behavior, it is appropriate and likely generative to examine it using an intertemporal choice framework, as rewarding behaviors (e.g., exercise; Albelwi, Rogers, \& Kubis, 2019) are temporally discounted similarly to material rewards (e.g., money; Green et al., 1994). A preliminary study towards this goal asked individuals to choose between hurting a provocative opponent a relatively small amount "now" or a larger amount "an hour later" (Chester et al., 2019a). This study provided evidence that people do engage in the delay discounting of aggression and that delayed-but-greater aggression choices are linked with greater activity in the ventromedial prefrontal cortex as is observed with the selection of delayed-but-greater monetary rewards (Chester et al., 2019a; Frost \& McNaughton, 2017). This initial foray supported the assertions that aggression is a rewarding behavior, that people prefer immediate rather than delayed revenge, and that an intertemporal choice framework is a viable new frontier for the study of aggression. A logical next step in this line of inquiry is to examine how such preferences may differ following interpersonal 
provocation.

Effects of Provocation. Insults, rejections, threats, snubs, taunts, and affronts of all types fall under the umbrella of interpersonal provocation. Such provocations likely affect individuals' intertemporal preferences for subsequent retaliation, as experimentally-induced provocation increases individuals' reward-seeking behavior (Baumeister, DeWall, Ciarocco, \& Twenge, 2005). Provocation also elicits angry rumination (Denson, Pedersen, Friese, Hahm, \& Roberts, 2011), which is reliably linked to delayed forms of revenge-seeking (Chester \& DeWall, 2018). Provoked individuals may therefore prefer delayed-but-greater retaliatory aggression as it satisfies their reward-seeking motivations by delivering a substantial and domain-specific reward (i.e., greater revenge).

Role of Antagonistic and Inhibitory Traits. One dispositional factor involved in retaliation is that of trait aggression. Trait aggression refers to an individual's tendency to engage in physical and verbal aggression (Buss \& Perry, 1992). Trait aggressiveness is associated with a greater tendency to derive hedonic pleasure from harming others (Chester, DeWall, \& Enjaian, 2019) and impaired inhibitory self-control (e.g., Keatley, Allom, \& Mullan, 2017). Such regulatory failures often manifest as a greater preference for immediate rewards (Lin \& Epstein, 2014). Greater trait aggression should thus be associated with a greater preference for immediate-but-lesser aggression due to its associations with uninhibited reward-seeking.

Some dispositional factors inhibit revenge-seeking. Trait self-control is the tendency to inhibit immediate impulses in service of longer-term goals and is an exemplar of an aggressioninhibiting factor (Denson, DeWall, \& Finkel, 2012). Indeed, self-control has been reliably implicated as a causal factor in reducing immediate retaliation to provocation (Denson et al., 2011; Finkel, DeWall, Slotter, Oaten, \& Foshee, 2009). Outside of the context of aggression, 
self-control is associated with a greater preference for delayed-but-greater rewards (Mishra \& Lalumière, 2017). Because of its ability to inhibit immediate retaliatory aggression and to promote the pursuit of delayed rewards, self-control should be positively associated with a preference for delayed-but-greater retaliation.

\section{The Present Research}

In this investigation we synthesized conceptual and methodological elements from both the delay discounting and aggression literatures to answer the overarching question: do people engage in the delay discounting of retaliatory aggression? We also sought to understand the situational and dispositional factors that affect intertemporal preferences for revenge. In Studies 1-2, we administered a behavioral measure of the delay discounting of aggression, while we experimentally manipulated provocation and measured antagonistic and inhibitory dispositions. In Studies 2-6 we implemented a new self-report measure of aggression discounting. Together, these studies served as the first systematic investigation of an intertemporal framework for aggression. The preregistered hypotheses and study protocol(s) are publicly available (https://osf.io/46pg7/wiki/), along with all de-identified data and code needed to reproduce our findings (https://osf.io/46pg7/files/). All study protocols were given ethics approval by the Virginia Commonwealth University institutional review board.

\section{Statistical Power Statement}

A priori power analyses were not used to determine the sample sizes in any of the six studies as no estimates of the hypothesized effect existed in the literature at the outset of the present research. Studies of aggression typically capture small-to-medium main effects, $r=.24$ (Richard, Bond, \& Stokes-Zoota, 2003). Thus, a minimum threshold of 130 participants provided 
at least $80 \%$ power to detect main effects of this magnitude or larger. Each of the six studies surpassed this threshold. Further, we conducted a sensitivity power analysis for each study to estimate the smallest effect size we could reliably power with each of our six samples.

\section{Study 1}

In Study 1 we implemented a laboratory paradigm that measured the extent to which participants temporally discounted revenge. We also administered measures of dispositional physical aggression and self-control. We expected that participants would exhibit a substantial preference for immediate-but-lesser over delayed-but-greater retaliatory aggression. We also predicted that experimentally-induced provocation would shift intertemporal preferences towards delayed-but-greater aggression. Finally, we expected that preferences for delayed-but-greater aggression would be associated with greater trait self-control and less trait aggression.

\section{Method}

\section{Participants}

Participants were 284 undergraduates: 170 females, 111 males, and 3 non-binary. See Supplemental Document 1 for full sample demographics of Studies 1-6.

\section{Materials}

Intertemporal Aggression Paradigm. To measure intertemporal preferences for retaliatory aggression, two classic research paradigms were combined to create the Intertemporal Aggression Paradigm (ITAP; Figure 1) - the Taylor Aggression Paradigm (Bushman \& Baumeister, 1998; Taylor, 1967) and a self-adjusting delay discounting task (Frye, Galizio, Friedel, Dehart, \& Odum, 2016). The ITAP was a computer-based, competitive reaction-time task that pit participants against a fictitious opponent to see who could press a button faster. Participants were informed by an experimenter that their opponent was completing a different 
study that required them to return the following day for another session. Participants were also informed that they would not need to return the following day themselves. At the outset of each trial participants chose between a lesser noise blast that was to be played through their opponent's headphones at the end of that trial or a louder noise blast that was administered later. Participants were then shown what their opponent selected and competed to press a button as fast as possible following a visual cue. If participants won the competition, they did not receive a noise blast. If they lost, they either heard a noise blast or were informed that they would receive a louder blast at the end of the study.

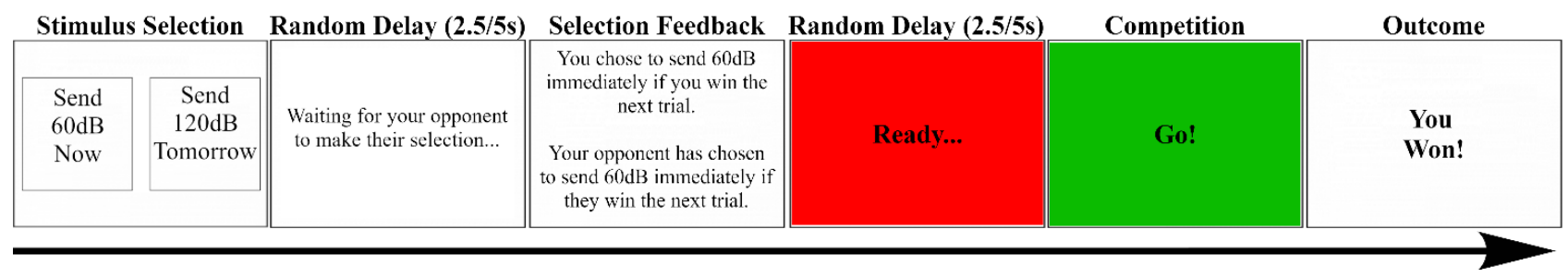

Figure 1. Series of events in an example ITAP trial. Values in parentheses represent randomly jittered durations in seconds(s). Events without parenthesized values had unlimited durations that required a keypress from the participant to proceed.

The ITAP consisted of two, 12-trial blocks (24 trials total). In the first block, the delayedbut-greater aggression option was associated with a delay of approximately one hour and in the second block, the delay was lengthened to approximately one day. The blocks were presented sequentially to all participants, as trial order does not impact estimates of delay discounting in tasks that adjust the amount of the immediate-but-lesser reward such as the ITAP (Holt, Green, \& Myerson, 2012).

The stated volume of the delayed-but-greater noise blast was held constant at 120 decibels (dB), though none of the noise blasts participants received exceeded 100dB to protect participant hearing. The volume of the immediate-but-lesser noise blast started at $60 \mathrm{~dB}$ on the 
first trial of each block and changed adaptively based on the decisions of the participant.

Selecting the immediate option decreased the volume of this option on the subsequent trial, whereas selecting the delayed option increased the volume of the immediate option on the subsequent trial. The amount that the volume was adjusted also decreased from trial-to-trial; starting at a $30 \%$ adjustment on the first trial of a given block, which was then reduced by approximately $4 \%$ on each subsequent trial. This adaptive calibration allowed for the calculation of subjective values of the delayed noise blast at each delay period (e.g., Friedel, DeHart, Madden, \& Odum, 2014). See Supplemental Document 2 for further details about the ITAP.

Brief Self-Control Scale. We administered the BSCS to assess trait self-control (Tangney, Baumeister, \& Boone, 2004). Participants indicated how accurately each of the 13 items represented themselves on a scale of 1 (not at all like me) to 5 (very much like me). Participants' trait self-control scores were computed as the mean of all 13 responses.

Buss-Perry Aggression Questionnaire. We used the BPAQ to measure trait physical aggression (Buss \& Perry, 1992). Participants endorsed 29 self-statements in terms of how accurately they represented themselves on a scale of 1 (extremely uncharacteristic of me) to 7 (extremely characteristic of me). Because the ITAP administered a form of physical aggression, we focused on the trait physical aggression subscale of the BPAQ. Participants' physical aggression scores were computed as the mean of their responses to the nine items of this subscale.

\section{Procedure}

Participants arrived at the laboratory individually for a one-hour study session ostensibly examining the impact of gaming experiences on reaction times. After providing informed consent, participants were screened for sensitive hearing, though none indicated hearing 
sensitivity. Participants completed a bogus video game experiences survey to maintain the cover story and were then introduced to the ITAP and completed three practice trials while the experimenter went to check on the ostensible opponent. All participants lost two of the three practice trials and were exposed to immediate sound blasts of 60 and 100dB. Participants viewed a 15-second 'connecting to partner' screen and then completed the 24-trial ITAP. Following the ITAP participants completed a single-item, ad hoc provocation manipulation check ("During the game you just played you were exposed to immediate blasts of aversive noises or accrued louder blasts of noise that are delayed until the end of the study. Which of the two did you find more provoking to receive?"). Responses to this question were recorded as 0 (the immediate noise) or 1 (the louder noises that will happen later). Next, participants completed an online questionnaire battery that included the BPAQ, BSCS, and demographic questions. Experimenters then administered a verbal, funnel interview to participants, which assessed suspicion surrounding the deceptive elements of the study. Participants were verbally asked "How are you feeling now that the study is over?", "Did you notice anything strange about the study?", and "What did you think of your opponent?" prior to being debriefed and excused. Recorded responses were then reviewed by the first author to determine levels of suspicion (see the "Suspicious Participants" section for more details).

\section{ITAP Scoring}

Preferences for delayed versus immediate aggression. To quantify the degree of preference for delayed versus immediate aggression on the ITAP, we divided the total number of each participant's delayed selections (coded as 1 ; immediate coded as 0 ) by the total number of trials (i.e., 24). Proportions were then multiplied by 100 to represent them as percentages.

Area under the curve. The self-adjusting feature of the ITAP allowed for the 
computation of each participant's area under the curve $(A U C)$, an index of the rate of each participant's aggression discounting. AUC values reflected the change in the subjective value of the delayed-but-greater ITAP option as a function of different delay lengths (i.e., one hour and one day). In the context of the ITAP, subjective value refers to the remaining proportion of the objective value of an aggression option (e.g., blasting the opponent with a $120 \mathrm{~dB}$ noise), after it has been discounted due to an associated delay (e.g., one day later). For example, if $120 \mathrm{~dB}$ were subjectively valued at $93 \mathrm{~dB}$ when paired with a one-day delay, then this delay reduced the subjective value of $120 \mathrm{~dB}$ to $77.50 \%$ of its objective value. To compute the $A U C$, we computed the subjective values of the delayed-but-greater aggression option for the one-hour and one-day delays. We computed each subjective value estimate by dividing the final adjusted decibel level of the immediate option on the last trial of each block by the objective value of delayed option (i.e., 120dB). Lower $A U C$ values represent greater discounting and higher $A U C$ values represent less discounting. $A U C$ values were computed for each participant using the equation detailed by Myerson, Green, \& Warusawitharana, 2001; see Supplemental Document 2 for more details regarding our computation of $A U C$ values).

\section{Results and Discussion}

\section{Descriptives}

Descriptive statistics are presented in Table 1. Due to a technical error, only $73.24 \%$ of our sample provided data from the provocation manipulation check. Univariate outliers beyond +/-3 SD from the mean were Winsorized. This method of handling outliers was applied consistently across Studies 1-6. A sensitivity analysis using G*power (Faul, Erdfelder, Lang, \& Buchner, 2007) indicated that our sample provided approximately $80 \%$ power for small effects $(d=0.17)$ for our paired-samples $t$-tests and correlational analyses $(r=.16)$. 
Table 1

Descriptive Statistics from Study 1

\begin{tabular}{lccccccc}
\hline Measure & $M$ & $S D$ & Skew & Kurtosis & $\omega$ & Missing & Outliers \\
\hline BPAQ-PA & 2.86 & 1.15 & 0.61 & -0.20 & .84 & 3 & 0 \\
BSCS & 3.04 & 0.65 & -0.01 & -0.24 & .81 & 0 & 0 \\
ITAP Area Under the Curve & 0.31 & 0.16 & 0.71 & -0.01 & - & 0 & 2 \\
ITAP \% Delayed & 30.96 & 21.96 & 0.47 & -0.15 & .86 & 0 & 1 \\
ITAP Subjective Value - One Day & 0.37 & 0.22 & 0.60 & -0.61 & - & 0 & 0 \\
ITAP Subjective Value - One Hour & 0.28 & 0.17 & 1.35 & 1.33 & - & 0 & 5 \\
Provocation Manipulation Check & 1.50 & 0.50 & -0.02 & -2.02 & - & 76 & 0 \\
\hline
\end{tabular}

Note. BPAQ-PA = physical aggression subscale of the Buss-Perry Aggression Questionnaire, $B S C S=$ Brief Self-Control Scale, ITAP = Intertemporal Aggression Paradigm, $\omega=$ McDonald's omega.

\section{Intertemporal Preferences}

As predicted, participants demonstrated a significantly greater preference for the immediate-but-lesser sound blast option, $t(283)=14.61, p<.001, d=0.87(95 \% C I=0.73,1.00$;

Figure 2). This effect replicates earlier, preliminary findings (Chester et al., 2019a) and indicates that the intertemporal preferences observed for aggression reflect those of other rewards (e.g., money; Green et al., 1994). 


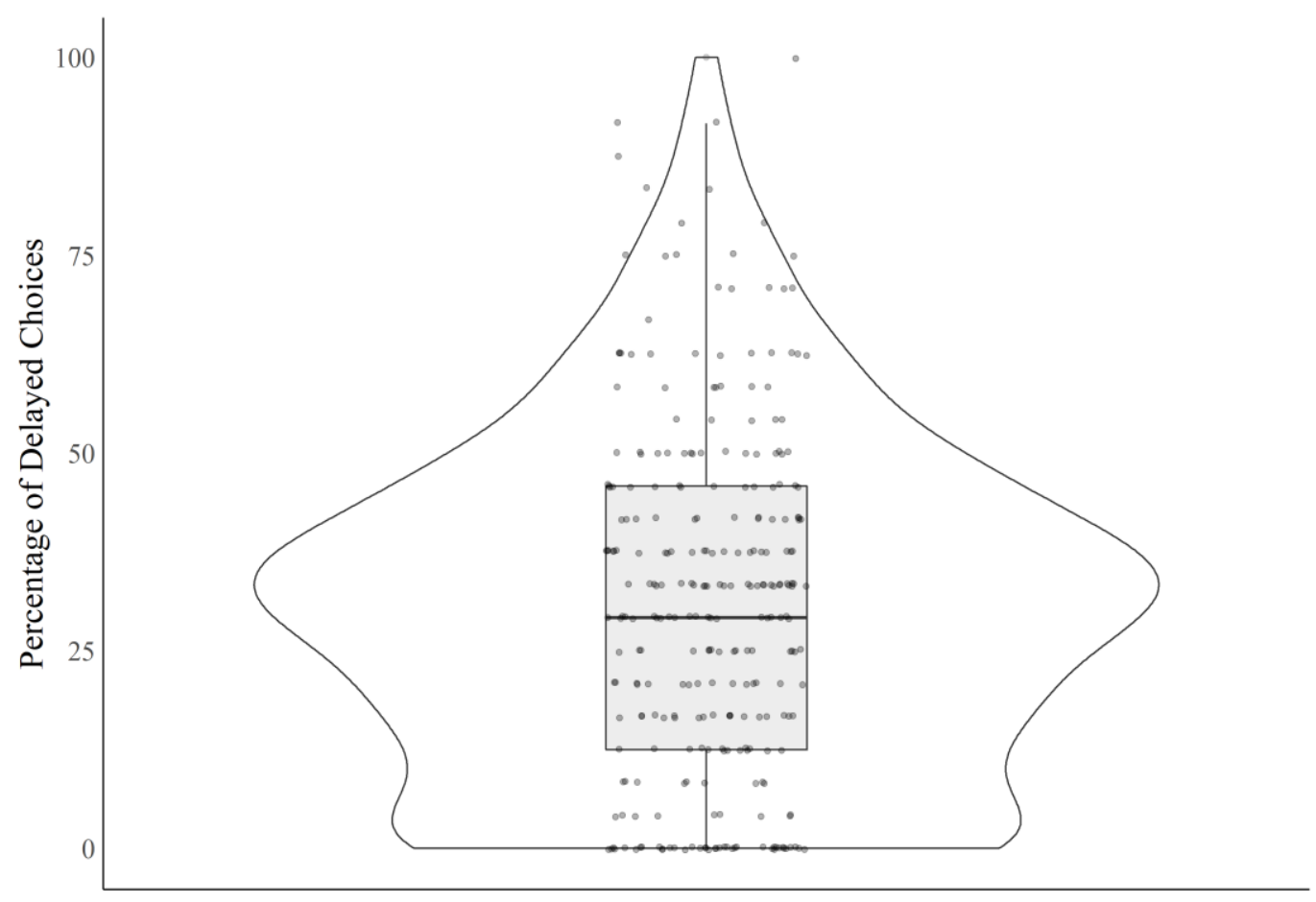

Figure 2. Percentage of delayed-but-greater aggression choices made across all trials in Study 1.

\section{Subjective Values}

Exploratory analyses revealed that, in contrast to much of the discounting literature (e.g., Mischel, Grusec, \& Masters, 1969), participants valued the delayed-but-greater aggression option more at the one-day delay, than at the one-hour delay, $t(283)=6.93, p<.001, d=0.41$ $(95 \% C I=0.29,0.53)$.

\section{Effect of Provocation}

Participants were nearly evenly divided in their provocation manipulation check responses, as $50.5 \%$ of participants indicated that the delayed-but-greater option was more provoking than the immediate-but-lesser noise blast. A paired-samples $t$-test among those who were more provoked by the immediate option revealed that these participants chose it more frequently following trials in which their opponent also selected it, $t(102)=3.36, p=.001, d=$ $0.33,95 \% \mathrm{CI}=0.13,0.53$. The same analysis among those who were more provoked by the 
delayed option revealed that they selected it more frequently following trials in which their opponent also selected the delayed option, $t(104)=5.23, p<.001, d=0.51,95 \% \mathrm{CI}=0.31,0.71$. Thus, consistent with prior research, provocation led participants to pursue the retaliation option they viewed as more aversive (Lawrence \& Hutchinson, 2013).

\section{Correlational Analyses}

Inconsistent with our expectations, participants higher in trait physical aggression selected a greater proportion of delayed responses, $r(278)=.18, p=.003$, though this association was not found with aggression discounting rates (Supplemental Document 3; Table S2). Similarly, trait self-control was not associated with any of the ITAP outcomes.

\section{Study 2}

In Study 1 we assumed that participants made choices by integrating information about both the volume of the noise blast and the associated delay. However, participants' preferences may have been based purely on one of these task elements (e.g., volume) and not both in conjunction. To address this limitation in Study 2, we included a block of the ITAP in which both options were delivered without delay, which allowed us to examine the association between aggressive behavior with and without an intertemporal choice component. To provide evidence of convergent validity for the ITAP and to extend our findings beyond the laboratory, we introduced a novel self-report measure of aggression discounting: the Aggression Choice Questionnaire (ACQ). As an exploratory aim we included measures of two more antagonistic dispositions: physical sadism and angry rumination. If intertemporal preferences for retaliation are truly reward-based considerations, then they should be associated with these traits which are typified by the hedonic enjoyment of harm-doing and mental practice of revenge, respectively (Chester et al., 2019b; Sukhodolsky, Golub, \& Cromwell, 2001). We expected to replicate our 
findings from Study 1, such that participants would demonstrate a substantial preference for the immediate-but-lesser option and would value the delayed option more as the delay increased.

\section{Method}

\section{Participants}

Participants were 265 undergraduates: 161 females, 102 males, one non-binary, one missing data.

\section{Materials}

Aggression Choice Questionnaire. The ACQ (Appendix A) was developed from the widely used Monetary Choice Questionnaire (MCQ; Kirby et al., 1999), which has been successfully adapted to measure the discounting of other rewards in the past (e.g., food; Hendrickson, Rasmussen, \& Lawyer, 2015). The MCQ asks participants to make 27 dichotomous choices between immediate-but-lesser and delayed-but-greater sums of money (e.g., “... \$14 today, or \$25 in 19 days?”). In contrast, the ACQ presented choices between inflicting immediate-but-lesser or delayed-but-greater amounts of hypothetical pain against a chosen target. The instructions of the ACQ first asked participants to "...take a moment and think about a person who has really hurt you." The ACQ then presented participants with a pain rating scale of 1 (very mild pain) to 10 (the worst possible pain) as a reference. Participants then made 27 intertemporal choices between inflicting an immediate-but-lesser or a delayed-butgreater level of pain on their chosen target (e.g., "Would you rather inflict pain level 4 right now or inflict pain level 8 in 260 days?"). To determine the pain levels and delay periods used for each of the ACQ items, we applied the equation used by the MCQ (Supplemental Document 4).

Participant responses on each ACQ item were coded: $0=$ immediate-but-lesser choice, 1 = delayed-but-greater choice. Unlike the discounting rates computed from the ITAP via $A U C$ the 
ACQ implements the discounting parameter $k$. Higher $k$ values reflect a greater degree of discounting and are thus inversely related to the AUC index of discounting used in the ITAP. Participant rates of aggression discounting were estimated using the same procedure implemented by the MCQ. We adapted a scoring tool made for the MCQ by Kaplan and colleagues (2016) that may be used to score ACQ data (Supplemental Document 5).

Angry Rumination Scale. The tendency to experience angry rumination was measured using the Angry Rumination Scale (ARS; Sukhodolsky, Golub, \& Cromwell, 2001). Participants were asked how frequently they experienced each of 19 examples of rumination on a scale of 1 (almost never) to 4 (almost always). Angry rumination scores were computed as the mean of all 19 responses for each participant.

Comprehensive Assessment of Sadistic Tendencies. The physical sadism subscale of the CAST was used to measure the tendency to enjoy inflicting physical harm on others (Buckles \& Paulhus, 2014). We focused on this subscale because the punishments available during the ITAP are a form of physical aggression. Participants rated five items on a scale of 1 (strongly disagree) to 7 (strongly agree). Physical sadism scores were computed as the mean of the five responses for each participant.

Intertemporal Aggression Paradigm. We expanded the ITAP in Study 2 such that we added three new blocks for a total of five, which introduced a more granular array of delaylengths: no delay, one hour, one day, four days, and one week. The number of trials per block were reduced to five in order to keep the task length (25 trials total) similar to Study 1. Unlike Study 1, the order of the blocks of the ITAP were randomized for each participant in Study 2.

Provocation Check. In Study 2 we introduced a longer instrument for measuring how participants perceived the soundblasts. This ad-hoc measure asked participants to indicate which 
of the two sound blast options were more accurately described by each of 15 attributes (e.g., Angering, Provoking, Stressful). Responses to this question were recorded as 0 (the immediate noise) or 1 (the louder noises that will happen later). Participant perception scores were computed as the mean of these 15 responses such that greater scores indicated perceiving the delayed soundblast as more aversive to receive.

\section{Procedure}

The procedure in Study 2 was identical to that of Study 1 excepting the information provided to participants regarding their opponent. After the experimenter introduced the ITAP, they informed participants that their opponent was completing a different study that required them to come back repeatedly over the next week, allowing participants to select noise blasts up to a week in the future.

\section{Results and Discussion}

\section{Descriptives}

Descriptive statistics are presented in Table 2. Sadism scores demonstrated positive skew and were subsequently base-10 log-transformed as doing so improves analytic properties (Chester et al., 2019b). A sensitivity analysis using G*power (Faul et al., 2007) indicated that our sample provided approximately $80 \%$ power for small effects for our planned repeated-measures analysis $\left(\eta_{\mathrm{p}}^{2}=.01\right)$, paired-samples $t$-tests $(d=0.17)$, and correlational analyses $(r=.17)$. Table 2

Descriptive and Reliability Statistics of all Variables in Study 2

\begin{tabular}{lccccccc}
\hline Measure & $M$ & $S D$ & Skew & Kurtosis & $\omega$ & Missing & Outliers \\
\hline ACQ $k$ & 0.17 & 0.11 & -0.73 & -1.35 & - & 56 & 0 \\
ACQ \% Delayed & 21.57 & 28.15 & 1.17 & 0.13 & .96 & 56 & 0 \\
ARS & 1.92 & 0.53 & 0.69 & 0.17 & .91 & 1 & 2 \\
BPAQ-PA & 2.67 & 1.00 & 0.57 & -0.04 & .78 & 1 & 0 \\
BSCS & 3.20 & 0.66 & -0.13 & -0.37 & .81 & 1 & 0 \\
\hline
\end{tabular}




\begin{tabular}{lccccccc}
\hline CAST-PS & 1.55 & 0.83 & 2.59 & 9.16 & .79 & 1 & 4 \\
ITAP Area Under the Curve & 0.31 & 0.14 & 1.27 & 1.67 & - & 0 & 5 \\
ITAP \% Delayed & 25.40 & 20.46 & 0.83 & 0.53 & .85 & 0 & 3 \\
ITAP Subjective Value - No Delay & 0.37 & 0.22 & 0.81 & -0.75 & - & 0 & 0 \\
ITAP Subjective Value - One Hour & 0.34 & 0.19 & 0.98 & 0.04 & - & 0 & 0 \\
ITAP Subjective Value - One Day & 0.33 & 0.18 & 1.05 & 0.28 & - & 0 & 0 \\
ITAP Subjective Value - Four Days & 0.30 & 0.17 & 1.33 & 1.07 & - & 0 & 7 \\
ITAP Subjective Value - One Week & 0.31 & 0.18 & 1.28 & 0.85 & - & 0 & 0 \\
Provocation Manipulation Check & 0.48 & 0.36 & 0.11 & -1.42 & .94 & 0 & 0 \\
\hline
\end{tabular}

Note. $A C Q k=$ discounting rates from the Aggression Choice Questionnaire, $A R S=$ Angry

Rumination Scale, BPAQ-PA = physical aggression subscale of the Buss-Perry Aggression Questionnaire, BSCS = Brief Self-Control Scale, CAST-PS = physical sadism subscale of the Comprehensive Assessment of Sadistic Tendencies, ITAP = Intertemporal Aggression Paradigm, $\omega=$ McDonald's omega.

\section{Intertemporal Preferences}

Participants greatly preferred the immediate noise blast option across all ITAP trials, $t(264)=19.57, p<.001, d=1.20,95 \% C I=1.04,1.36$ (Figure 3). Participants also significantly preferred the immediate option from the ACQ, $t(208)=14.60, p<.001, d=1.01,95 \% C I=0.84$, 1.18. These findings replicate our results from Study 1 and provide more evidence that people temporally discount retaliatory aggression. 


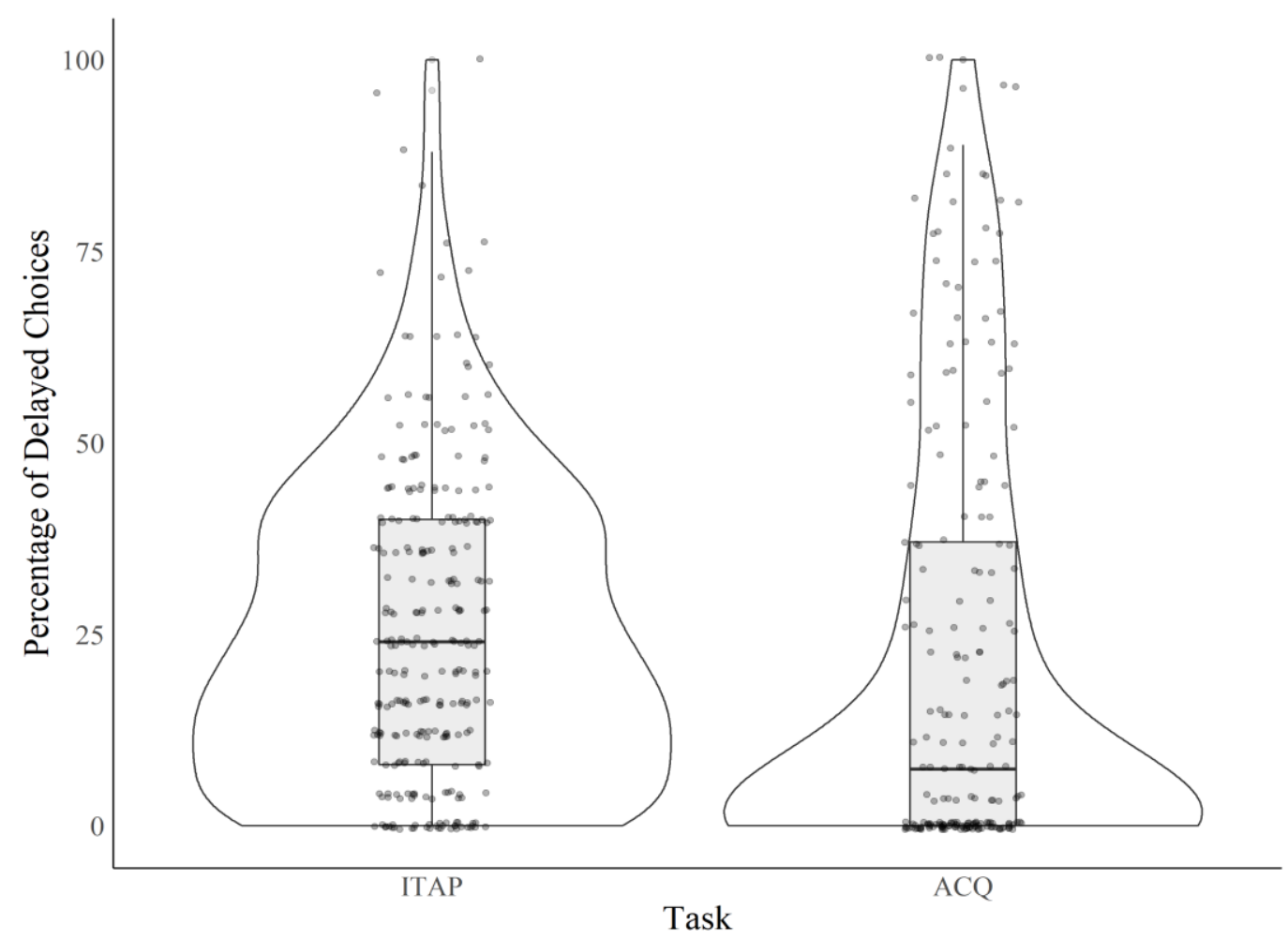

Figure 3. Percentage of delayed choices across all ITAP and ACQ trials in Study 2.

\section{Effects of Delay on the Value of Aggression}

We computed a repeated-measures ANOVA to test our hypothesis that subjective values of aggression would increase with greater delays during the ITAP. Delay blocks were dummy coded such that: $1=$ no delay, $2=$ one hour, $3=$ one day, $4=$ four days, and $5=$ one week. Mauchley's test of Sphericity indicated that the model violated the assumption of sphericity, $\chi^{2}(9)=73.80, p<.001$. We observed a significant Greenhouse-Geiser corrected main effect of delay block, $F(3.45,911.15)=8.42, p<.001, \eta_{\mathrm{p}}{ }^{2}=.03$, such that subjective values decreased as the delay increased (Figure 4). Within-subject polynomial contrasts also revealed a significant linear effect of delay, $F(1,264)=19.73, p<.001, \eta_{\mathrm{p}}^{2}=.07$, the quadratic, cubic, and quartic contrasts however did not yield significant effects (all $p \mathrm{~s}>.098$ ), suggesting that the effect of delay was indeed linear. Pairwise comparisons of the subjective value from each delay block 
against the No Delay block revealed that participants valued the louder sound blast more when there was no delay associated with it (Table 3).

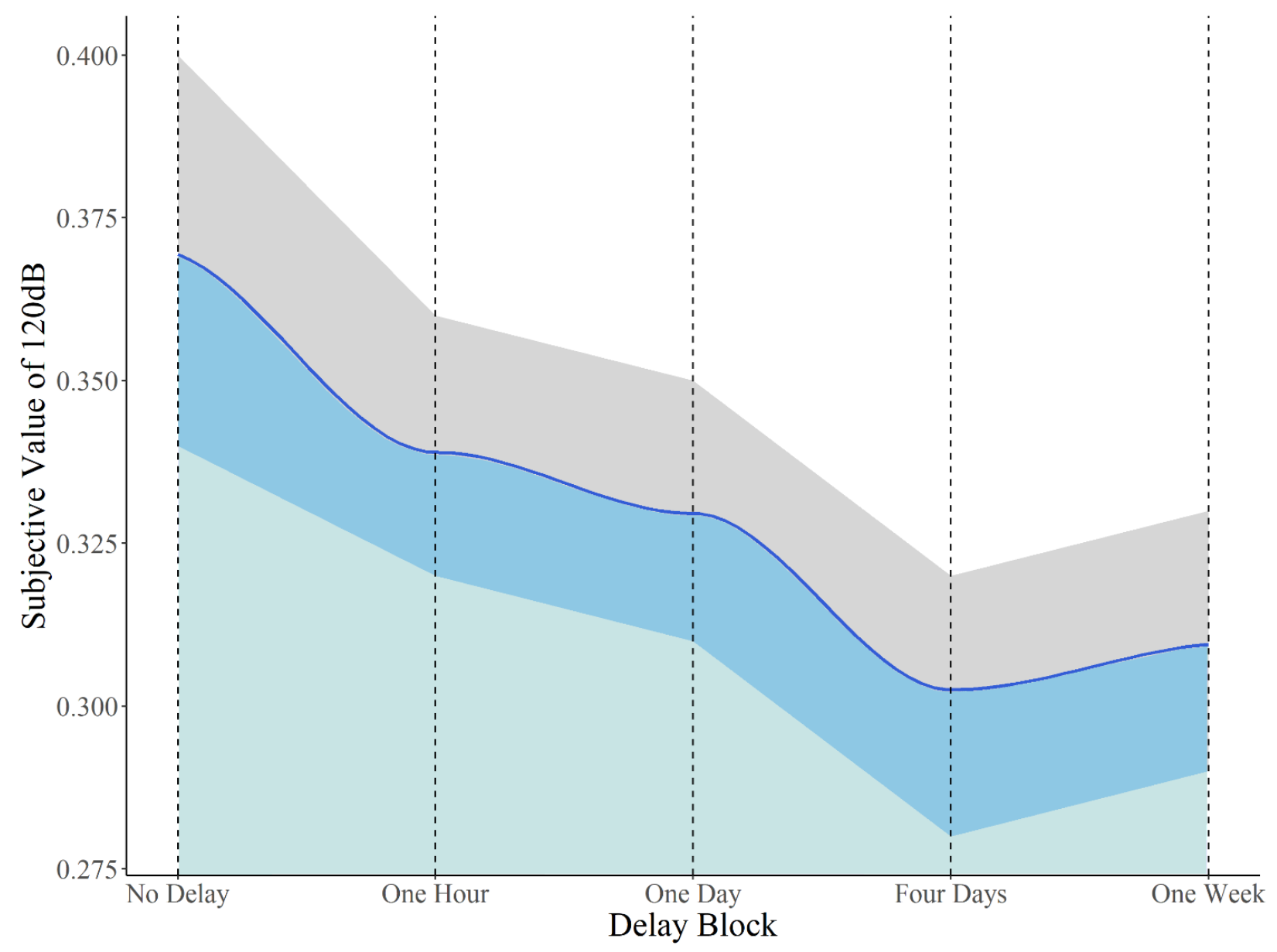

Figure 4. Discounting function observed in Study 2 from the ITAP. Shaded area around blue line represents $95 \%$ confidence interval around the mean subjective value of $120 \mathrm{~dB}$ at each delay.

Blue shaded region represents the average AUC for all participants.

Table 3

Planned Comparison of the Subjective Values of the Delayed 120dB Noise Blasts Against Those from the No Delay Block in the ITAP from Study 2

\begin{tabular}{lccc}
\hline Delay & $p$ & $d$ & $95 \% C I$ \\
\hline One hour & .026 & 0.14 & $0.04,0.30$ \\
One day & .006 & 0.17 & $0.01,0.33$ \\
Four days & $<.001$ & 0.27 & $0.07,0.41$ \\
\hline
\end{tabular}




\begin{tabular}{llll}
\hline One week & $<.001$ & 0.24 & $0.05,0.39$ \\
\hline
\end{tabular}

These results are inconsistent with our expectation and our finding from Study 1, in which participants valued the delayed aggression option more as the delay increased. This result is however consistent with the patterns of discounting found among other rewards (e.g., money; Kirby, 2009). As such, our finding from Study 1 may have been an artifact of the noncounterbalanced, sequential presentation of the blocks, which allowed experiences of provocation to accrue. This compounded provocation may have exacerbated the tendency to seek delayed-but-greater aggression. We observed a similar discounting function from the ACQ data, such that the subjective value of aggression decreased as the associated delay grew (Figure 5).

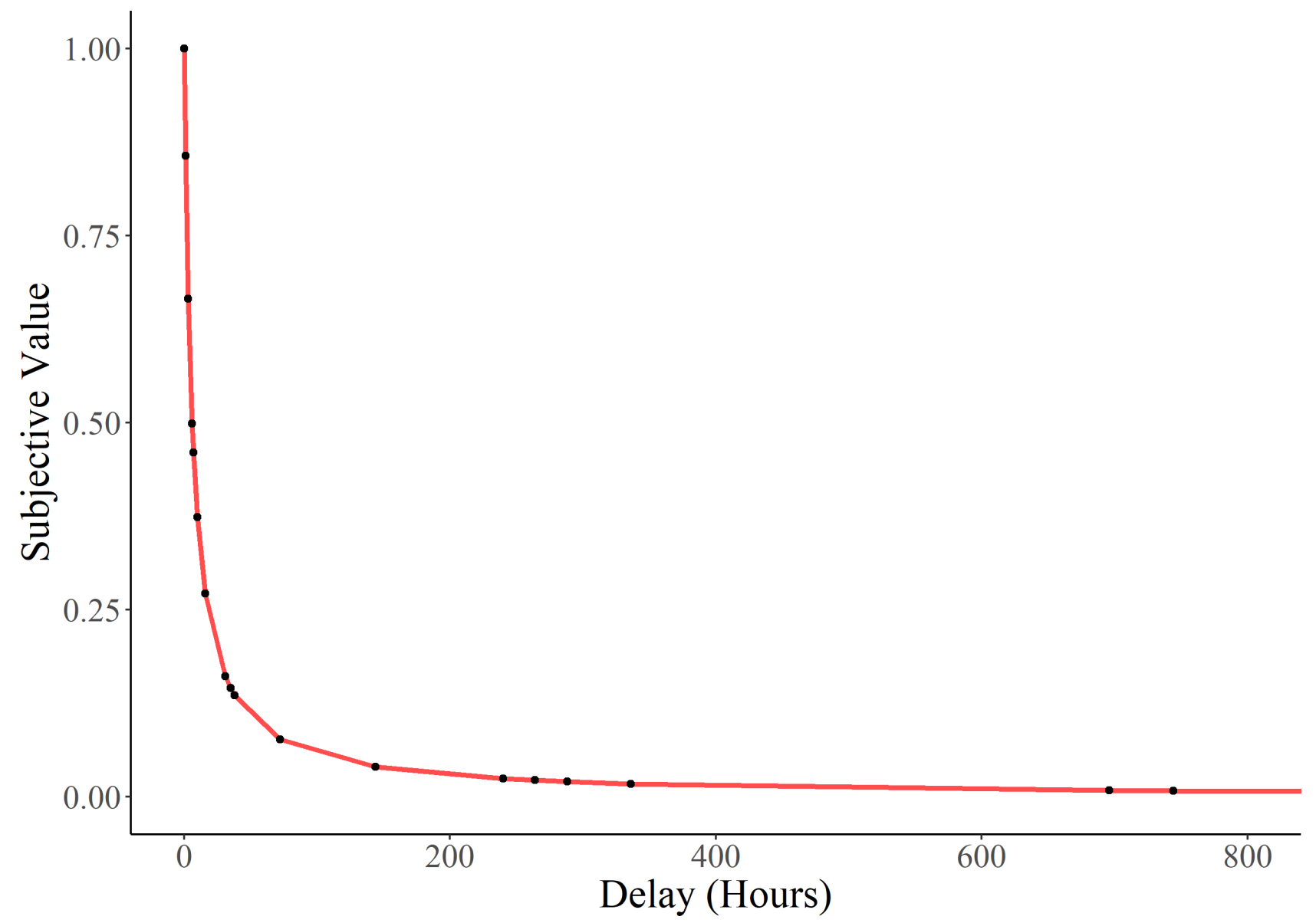

Figure 5. Discounting function observed in Study 2 from the ACQ. 


\section{Effect of Provocation}

Our expanded provocation check measure failed to provide a more decisive indication of how participants viewed the soundblasts as participants were largely split in their perceptions. The distribution of this variable was bimodal, such that the majority of participants were clustered at the ends of the distribution. As such, we conducted a median (.47) split to arrange participants into two groups: those who perceived the immediate-but-lesser soundblast as more aversive and those who perceived the delayed-but-greater soundblast as more aversive. Like Study $1,49.20 \%$ of participants indicated the delayed soundblast was more aversive to receive. We preregistered two moderation hypotheses that were made under the assumption that this variable would be normally distributed and would provide a more decisive indication of which option was more aversive to our participants. Given that these assumptions were not met, we abandoned these hypotheses.

To examine the effect of provocation we conducted a conceptual replication of the analyses from Study 1 by computing a paired-samples $t$-test among those who were more provoked by the immediate option which revealed that these participants chose it more frequently following trials in which their opponent also selected it, $t(131)=2.90, p=.004, d=$ $0.25,95 \% \mathrm{CI}=0.08,0.43$. Similarly, those more provoked by the delayed option selected it more frequently following trials in which their opponent selected the delayed option, $t(124)=$ $2.53, p=.013, d=0.23,95 \% C I=0.05,0.40$. These findings were consistent with those from Study 1.

\section{Convergent Validity and Trait Associations}

Exploratory zero-order correlations are presented in Supplemental Document 3 (Table S3). Discounting rates from the ACQ were negatively associated with those from the ITAP, 
$r(207)=-.20, p=.004$, providing evidence of convergent validity for both measures as the AUC and $k$ discounting parameters are inversely related. Physical sadism demonstrated a positive association with a preference for the delayed-but-greater ITAP option, $r(262)=.16, p=.011$. All remaining trait variables in Study 2 were unrelated with responses during the ITAP. See the Internal Meta-Analyses section for our inferences regarding trait associations with discounting rates from the ACQ.

\section{Disambiguating Magnitude and Timing}

Our inclusion of a no-delay block allowed for us to provide some further clarity on the motives behind participant choices during the delayed blocks of the ITAP. Specifically, it could have been that participants chose the delayed-but-greater option to delay punishment rather than in pursuit of greater retaliation. An exploratory bivariate correlation revealed a positive association between the number of louder sound blasts chosen during the No Delay block and those chosen during the delayed blocks, $r(262)=.53, p<.001$. Similarly, aggression discounting rates from the ACQ were negatively associated with the frequency of greater aggressive choices during the No Delay block of the ITAP, $r(206)=-.21, p=.003$, and those made during the delayed blocks of the ITAP, $r(206)=-.20, p=.004$. Thus, our data suggest that participants byand-large selected the delayed options during the ITAP and ACQ to inflict greater retaliation rather than as an attempt to delay retribution.

\section{Study 3}

In Study 3 we administered the ACQ following a social rejection manipulation to further examine the role of provocation in aggression discounting. Participants also completed measures of dispositional antagonism (i.e., angry rumination and physical aggression) and self-control. As in Study 2, we expected to find that rates of aggression discounting would be negatively 
associated with antagonistic traits and with a behavioral aggression measure that entailed no delay.

\section{Method}

\section{Participants}

Participants were 225 undergraduates: 178 females, 46 males, one missing data (Supplemental Document 1).

\section{Materials}

Brief Aggression Questionnaire. We used the BAQ, an abbreviated version of the BPAQ, to measure trait physical aggression (Webster et al., 2014). Trait physical aggression was measured using three items on a scale of 1 (strongly disagree) to 5 (strongly agree). Scores were computed as the mean of participant responses.

\section{Procedure}

Participants arrived at our laboratory individually to complete a study testing the impact of personality on social media preferences. After providing informed consent, participants completed a chatroom interaction with two ostensible chat partners, matched to participant gender (as in Donate et al., 2017). In reality, this task was programmed to simulate social exclusion, serving as the instigating factor in Study 3. All participants were ultimately rejected by the two chat partners, such that only $20 \%$ of all questions were directed at the participant. See Supplemental Document 6 for more details about the chatroom ostracism task. Participants then completed the Cold Pressor Aggression Task (CPAT) by selecting how long one of their chat partners would have to keep their hand submerged in ice-cold water on a scale of 1 ( 0 seconds) to 9 (80 seconds). Participants then completed a battery of questionnaires that included the ACQ, ARS, BAQ, BSCS, and demographics. Participants were then subjected to the same filtering 
interview detailed in Study 1 before they were debriefed and dismissed )see the "Suspicious

Participants" section for more details).

\section{Results and Discussion}

\section{Descriptive Statistics}

Descriptive statistics are provided in Table 4. A sensitivity analysis using G*power (Faul et al., 2007) indicated that our sample provided approximately $80 \%$ power for small effects $(d=$ $0.19)$ for our planned paired-samples $t$-tests and correlational analyses $(r=.18)$.

Table 4

Descriptive Statistics from Study 3

\begin{tabular}{lccccccc}
\hline Measure & $M$ & $S D$ & Skew & Kurtosis & $\omega$ & Missing & Outliers \\
\hline ACQ $k$ & 0.16 & 0.11 & -0.50 & -1.64 & - & 0 & 0 \\
ACQ \% Delayed & 23.69 & 30.42 & 1.10 & -0.01 & .97 & 0 & 0 \\
ARS & 1.87 & 0.61 & 0.95 & 0.65 & .94 & 0 & 1 \\
BAQ-PA & 2.38 & 1.07 & 0.35 & -0.85 & .74 & 0 & 0 \\
BSCS & 3.06 & 0.74 & 0.06 & -0.27 & .84 & 0 & 0 \\
CPAT & 3.66 & 1.88 & 0.99 & 0.31 & - & 1 & 0 \\
\hline
\end{tabular}

Note. $A C Q k=$ discounting rates from the Aggression Choice Questionnaire, $A R S=$ Angry

Rumination Scale, BAQ-PA = physical aggression subscale from the Brief Aggression Questionnaire, BSCS = Brief Self-Control Scale, CPAT = Cold Pressor Aggression Task, $\omega=$ McDonald's omega.

\section{Intertemporal Preferences}

Participants demonstrated a significant preference for the ACQ's immediate option, $t(224)=12.97, p<.001, d=0.87,95 \% \mathrm{CI}=0.71,1.02$.

\section{Association with Non-intertemporal Aggression}

Zero-order correlations are presented in Supplemental Document 3 (Table S4). As expected, aggressive behavior as measured by the CPAT and aggression discounting rates from the ACQ were negatively associated, $r(222)=-.14, p=.032$. Our inferences regarding associations of aggression discounting with trait angry rumination, physical aggression, and self- 
control were drawn from an internal meta-analysis (see the Internal Meta-Analysis section).

\section{Study 4}

Study 3 provided evidence that aggression discounting was negatively associated with retaliatory aggression. However, it remained unclear whether the provocation participants felt from the rejection manipulation in Study 3 causally impacted aggression discounting rates. This uncertainty stemmed from the fact that the manipulation used in Study 3 simulated a provoking chat partner who was not specified as the target for the ACQ. We addressed these limitations in Study 4 by implementing a between-subjects experimental design wherein participants were randomly assigned to ruminate about an individual who angered (i.e., provoked) or bored them in the past. The target of each participant's rumination then served as the target during the ACQ.

We deemed boredom to be a suitable control condition as it is a negatively valanced affective state that is linked with increased sensation-seeking and rumination (Bench \& Lench, 2019; Sousa \& Neves, 2020; van Tilburg \& Igou, 2017). Further, experiences of boredom and anger last approximately the same amount of time (i.e., two hours; Verduyn \& Lavrijsen, 2015). Boredom is also linked with greater instances of reactive and proactive aggression (Pfattheicher et al., 2020). Unlike anger, boredom is a low arousal experience that is not typified by the mental planning and rehearsal of retaliation involved in angry rumination (van Tilburg \& Igou, 2017).

We predicted that participants assigned to the angry rumination condition would exhibit significantly lower aggression discounting rates (i.e., a preference for delayed-but-greater vengeance) than would those in the boredom rumination condition. We also expected to replicate our prior findings that participants would demonstrate a significant preference for the immediatebut-lesser options during the ACQ.

\section{Methods}




\section{Participants}

Participants were 210 undergraduates: 159 females, 35 males, and 1 non-binary, 15 missing gender data; age: $M=18.59, S D=1.10$, range $=18-24($ Supplemental Document 1$)$.

\section{Measures}

Discrete Emotions Questionnaire. The state anger scale from the DEQ served as a manipulation check for the angry rumination induction (Harmon-Jones, Bastian, \& HarmonJones, 2016). This measure asked participants to report the extent to which they experienced various emotions (e.g., "Angry") during the essay writing task on a scale of 1 (not at all) to 7 (an extreme amount). We implemented items from the anger, fear, sadness, relaxation, and happiness sub-scales, reducing the 32-item measure to 20 items total. State anger scores were computed as the mean of the four items comprising this subscale.

\section{Procedure}

Participants signed up for a one-hour online study ostensibly examining the impact of personality traits on memory and decision-making. After providing informed consent participants were randomly assigned to either the angry rumination or boredom rumination condition. Those assigned to the angry rumination condition were asked to write about a provoking individual ("Take a moment and think of someone who has really hurt or angered you in the past. Once you have found such a person please write a detailed summary of what you remember about this event..."; Supplemental Document 7). Those in the boredom rumination condition were given identical instructions except they were asked to write about a person who bored them in the past. Participants were instructed to write about their recalled memory for 10 minutes. Such essay-writing manipulations have been successfully used to evoke various forms of rumination (e.g., Bushman, Bonacci, Pedersen, Vasquez, \& Miller, 2005; Denson et al., 2011). 
Following the writing task, participants completed the DEQ as a manipulation check and the ACQ. After completing the ACQ participants then completed a questionnaire battery including the ARS, BPAQ, BSCS, CAST, and a demographics questionnaire. We also included two attention check items that instructed participants to select a specific number from an array.

\section{Results and Discussion}

\section{Descriptives}

See Table 5 for descriptive statistics. As in Study 2, CAST scores exhibited significant skew and were thus base-10 log-transformed. A sensitivity analysis using G*power (Faul et al., 2007) indicated that our sample provided approximately $80 \%$ power for small effects for our planned independent-samples $t$-tests $(d=0.38)$ and correlational analyses $(r=.19)$.

Table 5

Descriptive Statistics from Study 4

\begin{tabular}{lccccccc}
\hline Measure & $M$ & $S D$ & Skew & Kurtosis & $\omega$ & Missing & Outliers \\
\hline ACQ $k$ & 0.19 & 0.09 & -1.38 & 0.13 & - & 0 & 0 \\
ACQ \% Delayed & 13.19 & 22.19 & 1.93 & 3.06 & .95 & 0 & 0 \\
Anger & 2.94 & 1.92 & 0.63 & -0.95 & .96 & 0 & 0 \\
ARS & 1.99 & 0.52 & 0.80 & 0.47 & .91 & 0 & 1 \\
BPAQ-PA & 2.70 & 1.02 & 0.47 & -0.38 & .78 & 19 & 1 \\
BSCS & 3.16 & 0.67 & 0.13 & -0.36 & .82 & 18 & 0 \\
CAST-PS & 1.46 & 0.75 & 2.18 & 4.79 & .79 & 45 & 2 \\
\hline
\end{tabular}

Note. $A C Q k=$ discounting rates from the Aggression Choice Questionnaire, ARS = Angry Rumination Scale, Anger = state anger from the DEQ, BPAQ-PA = physical aggression subscale from the Buss-Perry Aggression Questionnaire, BSCS = Brief Self-Control Scale, CAST-PS = physical Sadism subscale of the Comprehensive Assessment of Sadistic Tendencies, $\omega=$ McDonald's omega.

\section{Intertemporal Preferences}

We expected to find that as in Studies 1-3, participants would exhibit and overall preference for immediate-but-lesser vengeance. A paired-samples $t$-test supported this expectation, as participants demonstrated a significant preference for the immediate options during the ACQ, $t(209)=24.07, p<.001, d=1.66,95 \% \mathrm{CI}=1.45,1.87$. 


\section{Manipulation Check}

An independent-samples t-test revealed that those in the angry rumination condition reported significantly greater feelings of anger following the essay writing task than those in the boredom condition, $t(186.31)=9.65, p<.001, d=1.33,95 \% \mathrm{CI}=1.03,1.62$. This finding suggests that the rumination manipulation worked as intended.

\section{Effects of Anger Rumination on Aggression Discounting}

An independent-samples $t$-test revealed that, as expected, those in the anger condition (versus the boredom condition) exhibited significantly lower levels of aggression discounting, $t(189.71)=3.32, p=.001, d=0.46,95 \% \mathrm{CI}=0.18,0.73$. As such, individuals who completed the ACQ against an angering target were more likely to pursue delayed vengeance. This finding addresses the weaknesses from Study 3 as it provides direct evidence that provocative targets elicit motivation to delay retaliation in service of greater vengeance (i.e., less aggression discounting).

\section{Aggression Discounting and Trait Associations}

All zero-order correlations from Study 4 are available in Supplemental Document 3 (Table S5). See the Internal Meta-Analyses section for our inferences regarding trait associations.

\section{Study 5}

Studies 1-4 provided substantial evidence that people temporally discount retaliatory aggression. If our interpretations of these findings are correct, then aggression discounting should demonstrate characteristics like monetary discounting. One such characteristic is the temporal stability of discounting rates. Monetary discounting rates reliably demonstrate temporal stability in adults and have been characterized as trait-like (Kirby, 2009; Odum, 2011). We thus 
examined the extent to which aggression discounting mirrored the discounting of monetary rewards in Study 5.

We expected that aggression discounting rates would demonstrate temporal stability like that of monetary discounting rates. Next, we expected that rates of aggression discounting would be significantly greater than monetary discounting. This prediction was based on findings that experiential rewards are often discounted to a greater extent than material rewards (e.g., exercise; Albelwi et al., 2019). We also expected to replicate our findings from Studies 2-4 that antagonistic traits would be negatively associated with discounting rates from the ACQ. To demonstrate the specificity of these trait effects to aggression discounting, we predicted that antagonistic dispositions would not be associated with rates of monetary discounting. Finally, we expected that trait self-control would be negatively associated with discounting rates from both tasks. We also aimed to examine decision conflict experienced during the ACQ and MCQ by implementing an internet-based mousetracking implementation, but this implementation failed to record these data accurately and thus we were unable to test the relevant preregistered hypotheses.

\section{Method}

\section{Participants}

Participants at Time 1 were 273 undergraduates: 174 females, 93 males, and 2 nonbinary, 4 missing data. Participants at Time 2 were 110 undergraduates: 69 females, 40 males, 1 missing data.

\section{Measures}

Monetary Choice Questionnaire. The 27-item version of the MCQ (Kirby et al., 1999) was used to assess the delay discounting of monetary rewards. Participants made 27 
intertemporal choices regarding varying amounts of money and periods of delay. We calculated discounting rates $(k)$, from the MCQ using an automatic scoring tool (Kaplan et al., 2016). Procedure

Participants signed up for a two-part online study examining the effects of gaming experiences on reaction times. Each session was approximately 30 minutes in length and participants were required to wait a minimum of three weeks before completing the second session. Each session included an identical battery of measures, excepting the order in which the ACQ and MCQ were presented, which was randomly counterbalanced within each session. After completing these two discounting measures, participants then completed the BPAQ, CAST, BSCS, ARS, and a demographics questionnaire. Given that Study 5 was an online study, we included two attention check items per session that instructed participants to select a specific number from an array. Participants were contacted via email three weeks later with instructions for completing the second session, after which they were debriefed.

\section{Results and Discussion}

\section{Descriptives}

Descriptive statistics are provided in Table 6. Participants waited an average of 28.01 days, $S D=8.87$, range $=21-73$, median $=24.50$, to complete the second session. Seven participants from Time 1 and four participants from Time 2 failed both attention check questions and were thus excluded from analyses. CAST scores exhibited significant skew and were thus base-10 log-transformed. MCQ scores were also transformed in this manner due to the observed skew. A sensitivity analysis using $\mathrm{G}^{*}$ power (Faul et al., 2007) indicated that our sample provided approximately $80 \%$ power for small effects (Time 1: $d=0.17$; Time $2: d=0.28$ ) for our planned paired-samples $t$-tests and correlational analyses (Time 1: $r=.17$; Time 2: $r=.27$ ). 
Table 6

Descriptive Statistics from Study 5 at Time 1 and Time 2

\begin{tabular}{lccccccc}
\hline Measure & $M$ & $S D$ & Skew & Kurtosis & $\omega$ & Missing & Outliers \\
\hline Time 1 & & & & & & & \\
ACQ $k$ & 0.13 & 0.11 & -0.02 & -1.90 & - & 0 & 0 \\
ACQ \% Delayed & 30.49 & 29.10 & 0.51 & -1.00 & .95 & 0 & 0 \\
ARS & 1.96 & 0.62 & 0.89 & 0.79 & .95 & 0 & 4 \\
BPAQ-PA & 2.81 & 1.15 & 0.40 & -0.70 & .84 & 10 & 0 \\
BSCS & 3.08 & 0.70 & 0.09 & -0.22 & .84 & 0 & 0 \\
CAST-PS & 1.73 & 0.96 & 1.98 & 5.37 & .83 & 8 & 0 \\
MCQ $k$ & 0.03 & 0.05 & 2.90 & 9.33 & - & 0 & 0 \\
MCQ \% Delayed & 43.53 & 20.18 & 0.57 & 0.50 & .91 & 0 & 0 \\
& & & & & & & \\
Time 2 & & & & & & & \\
ACQ $k$ & 0.14 & 0.11 & -0.20 & -1.83 & - & 0 & 0 \\
ACQ \% Delayed & 25.75 & 28.49 & 0.84 & -0.49 & .95 & 0 & 0 \\
ARS & 1.89 & 0.58 & 0.58 & -0.11 & .94 & 2 & 1 \\
BPAQ-PA & 2.66 & 1.14 & 0.78 & 0.03 & .86 & 1 & 1 \\
BSCS & 3.07 & 0.69 & 0.26 & -0.01 & .85 & 1 & 0 \\
CAST-PS & 1.76 & 1.07 & 2.16 & 5.80 & .97 & 2 & 1 \\
MCQ $k$ & 0.03 & 0.05 & 2.75 & 8.73 & - & 0 & 0 \\
MCQ \% Delayed & 43.67 & 21.28 & 0.43 & 0.06 & .91 & 0 & 0 \\
\hline
\end{tabular}

Note. ACQ $k=$ discounting rates from the Aggression Choice Questionnaire, ARS = Angry Rumination Scale, BPAQ-PA = physical aggression subscale of the Buss-Perry Aggression Questionnaire, BSCS = Brief Self-control Scale, CAST-PS = physical sadism subscale of the Comprehensive Assessment of Sadistic Tendencies, $M C Q k=$ discounting rates from the Monetary Choice Questionnaire, $\omega=$ McDonald's omega.

\section{Test-Retest Reliability}

Consistent with our expectations, rates of aggression discounting measured by the ACQ demonstrated a strong, positive association across timepoints, $r(102)=.63, p<.001$. Discounting rates from the MCQ demonstrated similar test-retest reliability, $r(102)=.67, p<.001$.

\section{Response Preferences and Discounting Rates}

Consistent with our predictions and findings from Studies 1-4, participants preferred the immediate-but-lesser option during both the ACQ and MCQ at both timepoints (Table 7).

Table 7 
Paired-Samples t-Test Results Comparing the Number of Immediate to Delayed Choices

\begin{tabular}{lccccc}
\hline & $t$ & $d f$ & $p$ & $d$ & $95 \% C I$ \\
\hline ACQ Time 1 & 10.93 & 265 & $<.001$ & 0.67 & $0.54,0.80$ \\
ACQ Time 2 & 9.14 & 104 & $<.001$ & 0.89 & $0.66,1.12$ \\
MCQ Time 1 & 5.23 & 265 & $<.001$ & 0.32 & $0.20,0.44$ \\
MCQ Time 2 & 2.67 & 104 & .009 & 0.26 & $0.07,0.46$ \\
\hline
\end{tabular}

Participant discounting rates for aggression were greater than those for money at both

Time $1, t(265)=12.47, p<.001, d=0.76(95 \% C I=0.63,0.90)$, and Time $2, t(104)=8.73, p<$ $.001, d=0.85,95 \% \mathrm{CI}=0.63,1.07$ (Figure 6). This finding supports our hypothesis and suggests that aggression, like other experiential rewards, is discounted more steeply than tangible rewards such as money (Albelwi et al., 2019).

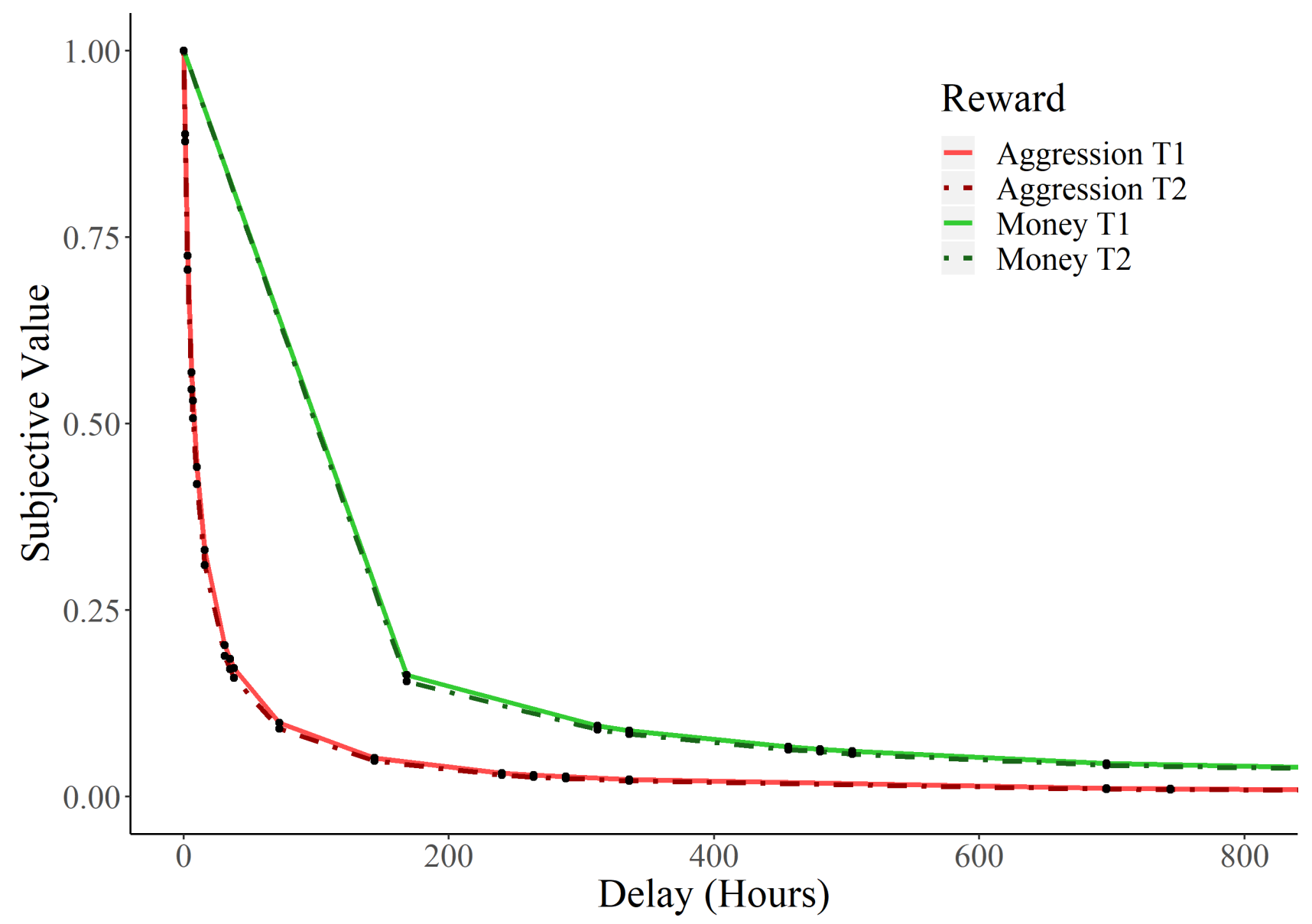

Figure 6. Observed discounting functions for aggression and money from Time 1 (T1) and Time 
2 (T2).

\section{Trait Associations with Monetary Discounting}

Zero-order correlations are presented in Supplemental Document 3 (Table S6). We found no support for our prediction that trait self-control would be associated with discounting rates from the MCQ (all $p s>$.669). Consistent with our expectations, antagonistic traits were not associated with rates of monetary discounting at Time 1 or Time 2 (all $p \mathrm{~s}>.062$ ). See the Internal Meta-Analyses section for inferences regarding trait associations with rates of aggression discounting.

\section{Study 6}

To identify other ways in which aggression discounting either paralleled or was distinct from other domains of delay discounting, we further contrasted elements of aggression and monetary discounting in Study 6. One crucial element to intertemporal choice that we examined was decision conflict, the amount of cognitive effort involved in deciding between two or more attractive options (Houston \& Doan, 1996). We tested the hypothesis that discounting rates would be negatively associated with decision conflict for aggression and monetary sums.

We further predicted that discounting rates and decision conflict estimates would be positively associated across the ACQ and MCQ. We also expected that trait self-control would be associated with faster conflict resolution for delayed choices, and as demonstrated by prior research (Gillebaart, Schneider, \& De Ridder, 2016). Lastly, we expected to replicate the preference for immediate revenge observed in Studies 1-5 and for immediate monetary rewards as in Study 5.

\section{Method}

\section{Participants}


Participants were 256 undergraduates: 158 females, 92 males, 3 non-binary, 3 missing data (See Supplemental Document 1).

\section{Measures}

Decision conflict. The Mousetracker program was used to record computer mouse movements to index the extent of conflict participants evinced during the ACQ and MCQ (Freeman \& Ambady, 2010). We used the maximum deviation (i.e., the maximum distance the cursor deviates from the most direct path to an eventual choice) index of conflict as estimated by the Mousetracker (Mckinstry, Dale, \& Spivey, 2008). Mean conflict values were then computed for all trials during the MCQ and ACQ. We also computed mean conflict values for all trials that resulted in 'delayed' and 'immediate' choices for both tasks. Raw mouse trajectory data was processed, time normalized, and visualized using the Mousetrap package for R version 4.0.2 (Wulff, Haslbeck, Kieslich, Henninger, \& Schulte-Mecklenbeck, 2019).

\section{Procedure}

Participants arrived at the lab in groups of up to five to complete a study examining the effect of gaming experiences on reaction times. After providing informed consent, participants completed the ACQ and MCQ. The Mousetracker versions of the ACQ and MCQ differed from the traditional self-report versions in two ways. First, the immediate and delayed options were clickable boxes in the upper left and right corners of the screen, respectively. Second, the participant's mouse cursor began each trial in a box labeled "Start" that was positioned in the bottom center of the screen. The order in which the ACQ and MCQ were presented was counterbalanced across participants such that half completed the ACQ first and the rest completed the MCQ first. Participants then completed a questionnaire battery including the BPAQ, ARS, BSCS, CAST, and a demographics questionnaire. Participants were then debriefed. 


\section{Results and Discussion}

\section{Descriptives}

See Table 8 for descriptive statistics. Participant scores from the MCQ and CAST violated assumptions of normality and were base-10 log-transformed. A sensitivity analysis using G*power (Faul et al., 2007) indicated that our sample provided approximately $80 \%$ power for small effects for our planned paired-samples $t$-tests $(d=0.18)$ and correlational analyses $(r=.17)$.

Table 8

Descriptive Statistics from Study 6

\begin{tabular}{lccccccc}
\hline Measure & $M$ & $S D$ & Skew & Kurtosis & $\omega$ & Missing & Outliers \\
\hline ACQ $k$ & 0.13 & 0.11 & -0.12 & -1.81 & - & 0 & 0 \\
ACQ MD & 0.28 & 0.21 & 0.85 & 0.72 & - & 0 & 4 \\
ACQ \% Delayed & 27.47 & 27.29 & 0.86 & -0.18 & .94 & 0 & 0 \\
ARS & 2.03 & 0.59 & 0.83 & 0.60 & .93 & 0 & 1 \\
BPAQ-PA & 2.82 & 1.15 & 0.61 & -0.08 & .84 & 3 & 0 \\
BSCS & 2.99 & 0.73 & 0.22 & -0.22 & .86 & 0 & 0 \\
CAST-PS & 1.52 & 0.68 & 1.85 & 3.95 & .71 & 0 & 1 \\
MCQ $k$ & 0.03 & 0.04 & 2.80 & 10.36 & - & 0 & 3 \\
MCQ MD & 0.39 & 0.23 & 0.23 & -0.64 & - & 0 & 0 \\
MCQ \% Delayed & 38.44 & 16.02 & 0.87 & 1.54 & .70 & 0 & 3 \\
\hline
\end{tabular}

Note. $A C Q k=$ discounting rates from the Aggression Choice Questionnaire, $A R S=$ Angry Rumination Scale, BPAQ-PA = physical aggression subscale of the Buss-Perry Aggression Questionnaire, BSCS = Brief Self-control Scale, CAST-PS = physical sadism subscale of the Comprehensive Assessment of Sadistic Tendencies, $M C Q k=$ discounting rates from the Monetary Choice Questionnaire, MD = maximum mouse deviation, $\omega=$ McDonald's omega.

\section{Magnitudes of Conflict}

In support of our hypothesis, participants exhibited greater conflict (Figure 7) when making delayed-choice ACQ trials, as compared to immediate-choice trials, $t(186)=4.25, p<$ $.001, d=0.31,95 \% \mathrm{CI}=0.16,0.46$. Conversely (and against predictions), participants demonstrated significantly less conflict during delayed-choice trials on the MCQ, $t(252)=-2.55$, $p=.011, d=-0.16,95 \% \mathrm{CI}=-0.28,-0.04$. As predicted, conflict was positively associated between the ACQ and MCQ, $r(254)=.45, p<.001$. Taken together, these findings suggest that 
the conflict experienced during intertemporal choice for money and aggression were similar, but that greater cognitive effort was involved in making delayed-but-greater aggression decisions and immediate-but-lesser financial decisions.

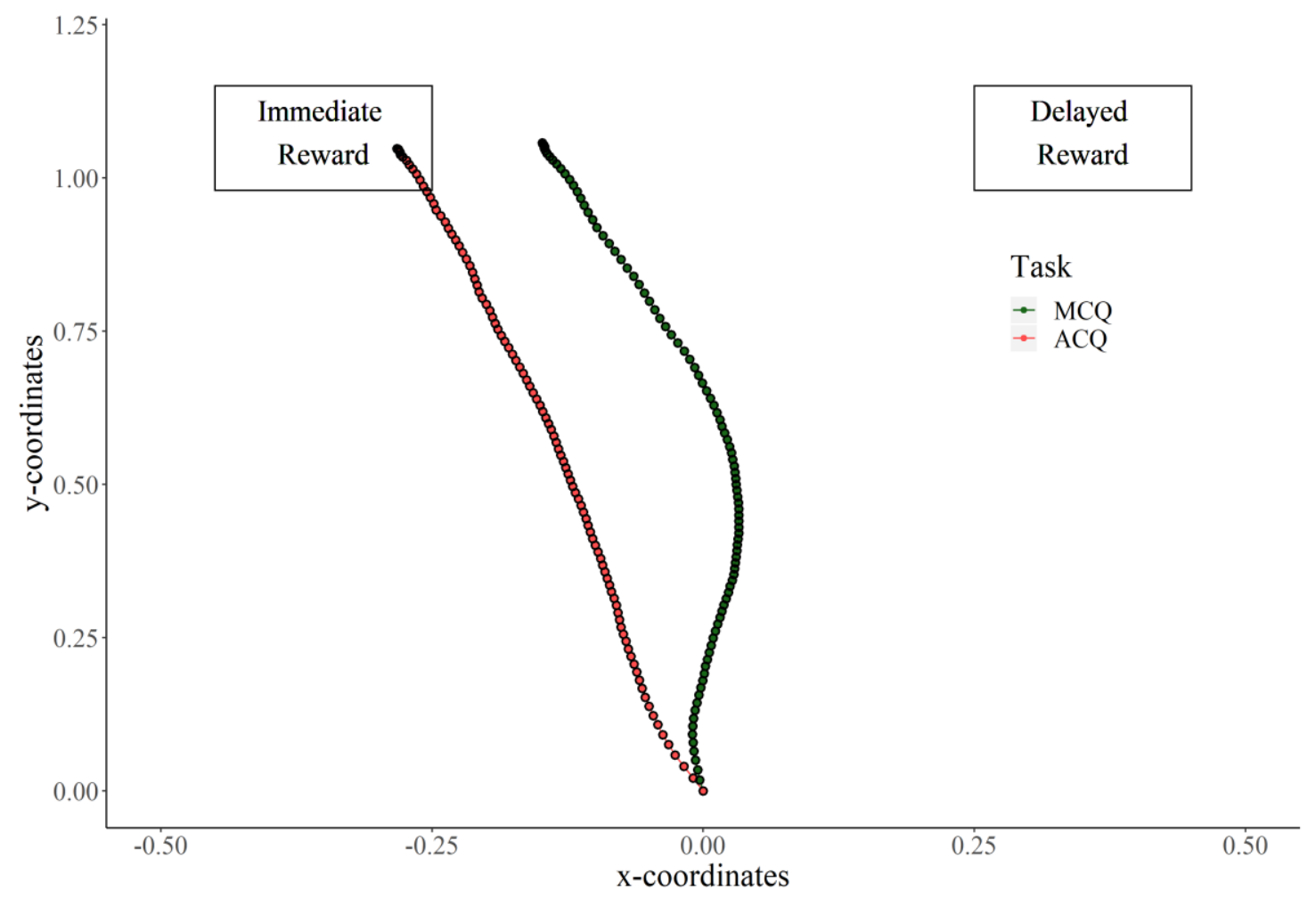

Figure 7. Mean mouse trajectories across all trials of the ACQ (red) and MCQ (green) in Study 6.

\section{Discounting Rate and Trait Associations}

Zero-order correlations from Study 6 are presented in Supplemental Document 3 (Table S7). Rates of monetary and aggression discounting were negatively associated, $r(254)=-.13, p=$ .046 , the opposite of our expectations. See the Internal Meta-Analyses section for our inferences regarding trait associations. Exploratory correlations revealed that antagonistic dispositions were positively associated with the amount of conflict exhibited during the ACQ, but not MCQ. These findings suggest that intertemporal preferences for delayed revenge among more antagonistic individuals entail greater cognitive conflict. Unexpectedly, trait self-control was unassociated 
with conflict from either discounting task.

\section{Response Preferences and Discounting Rates}

Consistent with our findings from Studies 1-5 and our expectations, participants greatly preferred the immediate option during the ACQ, $t(255)=13.21, p<.001, d=0.83,95 \% \mathrm{CI}=$ 0.68, 0.97. Participants also preferred the immediate option during the MCQ, $t(255)=11.54, p<$ $.001, d=0.72,95 \% \mathrm{CI}=0.58,0.86$. Consistent with our finding from Study 4 , a paired-samples $t$-test indicated that discounting rates $(k)$ were greater for aggression than money, $t(255)=14.06$, $p<.001, d=0.88,95 \% \mathrm{CI}=0.73,1.02$ (Figure 8 ).

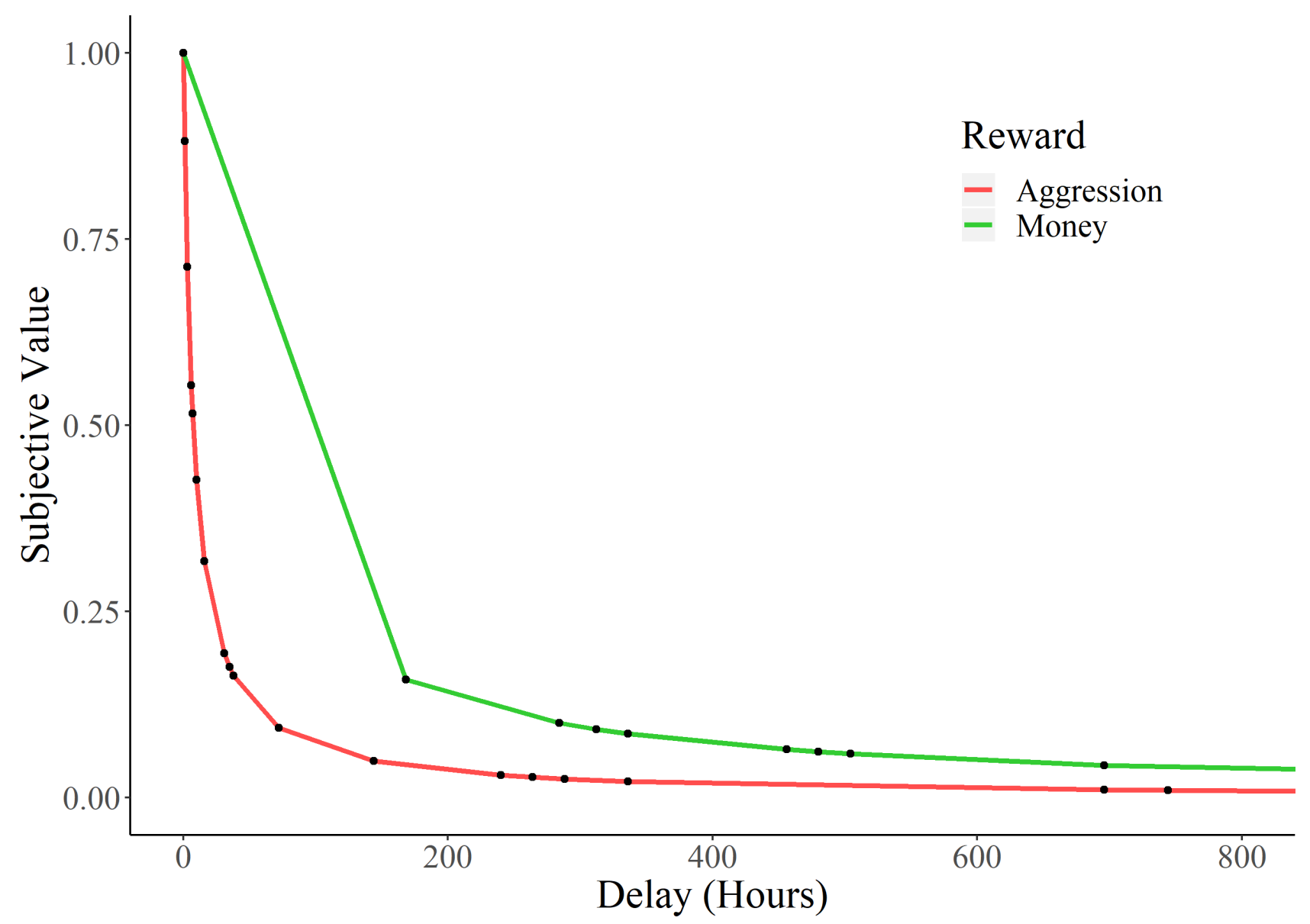

Figure 8. Discounting functions for aggression (red) and money (green) observed in Study 5.

\section{Internal Meta-Analyses}

Across our studies we repeatedly tested whether various antagonistic and inhibitory traits 
were linked to aggression discounting. To estimate these effects across all our studies, we conducted random-effects meta-analyses on the association between aggression discounting from the ACQ and each dispositional variable using the metafor package for R version 4.0.2 (R Core Team, 2020). We observed negative associations between the antagonistic traits and rates of aggression discounting (Table 9). Conversely, we found a significant positive association between trait self-control and aggression discounting.

Table 9

Meta-Analytic Associations Between Aggression Discounting and Trait Variables

\begin{tabular}{lccccccccc}
\hline Trait & $r$ & $95 \% C I$ & $S E$ & $Z$ & $p$ & $N$ & $k$ & $Q$ & $p_{Q}$ \\
\hline ARS & -.22 & $-0.29,-0.14$ & 0.04 & -5.63 & $<.001$ & 1,155 & 5 & 7.10 & .131 \\
BPAQ-PA & -.22 & $-0.29,-0.16$ & 0.03 & -6.70 & $<.001$ & 1,136 & 5 & 5.21 & .266 \\
CAST-PS & -.17 & $-0.27,-0.06$ & 0.06 & -3.00 & .027 & 885 & 4 & 8.85 & .031 \\
BSCS & .08 & $0.01,0.15$ & 0.04 & 2.19 & .029 & 1,137 & 5 & 6.25 & .181 \\
\hline
\end{tabular}

Note. $A R S=$ Angry Rumination Scale, BPAQ-PA = physical aggression subscale of the BussPerry or Brief Aggression Questionnaire, BSCS = Brief Self-control Scale, CAST-PS = log transformed physical sadism subscale of the Comprehensive Assessment of Sadistic Tendencies.

We also conducted internal meta-analyses examining two of our focal hypotheses. Our hypothesis that participants would prefer the lesser-but-immediate aggression option yielded a large meta-analytic effect, $d=0.91, \mathrm{SE}=0.08, Z=10.95, p<.001,95 \%$ CI: $0.75,1.07, Q=$ $29.04, p_{Q}<.001$. In contrast, our hypothesis that provoking targets would yield less aggression discounting yielded a small meta-analytic effect, $d=0.36, \mathrm{SE}=.14, Z=2.50, p=.013,95 \% \mathrm{CI}$ : 0.09, 0.65, $Q=4.26, p_{Q}=.039$. See Supplemental Document 8 for further details about our internal meta-analyses.

\section{High and Low Aggression Discounters}

\section{Bimodal Distributions of Aggression Discounting}


We reliably observed bimodal distributions of aggression discounting rates from the ACQ across Studies 2-6 (Figure 9), but not among the monetary discounting rates measured in Studies 5-6. To examine whether these bimodal distributions reflected meaningful distinctions between our participants, we conducted $k$-means cluster analyses for each study containing ACQ data. Results of this analysis converged after a single iteration in each sample, separating participants into groups of high $(N=620)$ and low $(N=442)$ aggression discounters (see Supplemental Document 8 for more details).

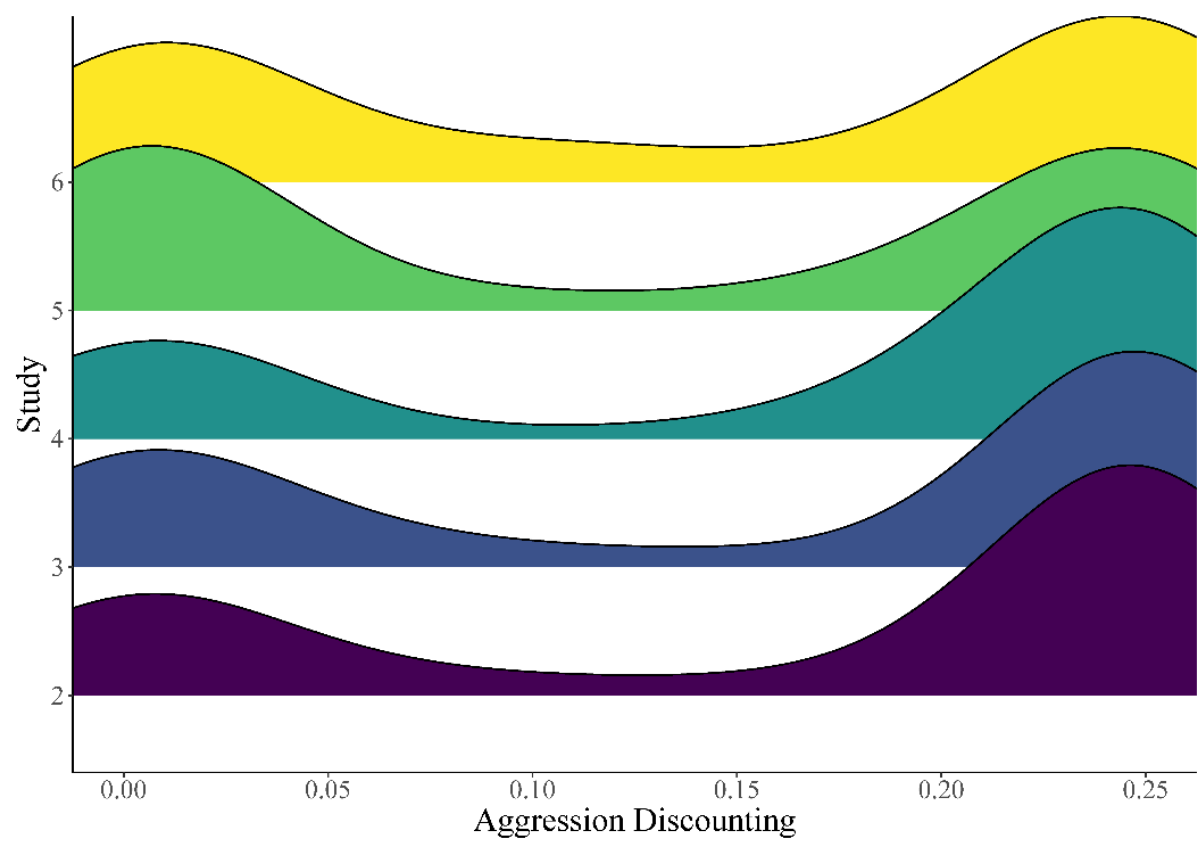

Figure 9. Distributions of aggression discounting rates from the ACQ across Studies 2-6.

\section{Cluster-wise Differences in Aggression Discounting}

Combining across all five studies that provided ACQ data ${ }^{2}$, we observed dramatically different aggression discounting functions between the 'high' and 'low' aggression discounting clusters. As an example of the magnitude of this between-cluster distinction in aggression discounting functions, the delayed-but-greater aggression option was subjectively valued at less than $10 \%$ of its objective value after 39.50 hours for the 'high discounters' cluster and after

${ }^{2}$ We only included data from the anger condition from Study 4 and from Time 1 from Study 5 in these analyses. 
443.50 hours for the 'low discounters' cluster. Further, low aggression discounters demonstrated a discounting curve for monetary sums like their discounting function for aggression, whereas high aggression discounters demonstrated a steeper discounting curve for aggression than money (Figure 10).
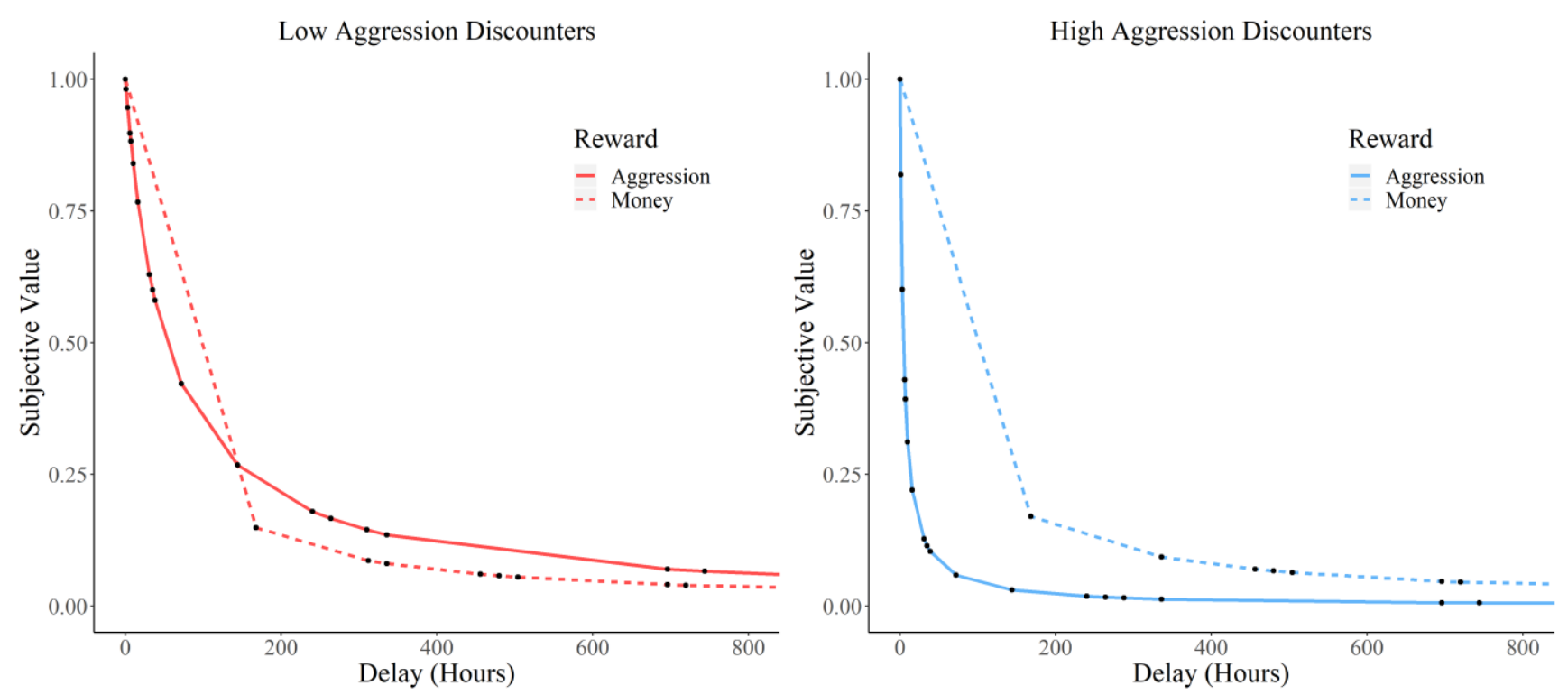

Figure 10. Combined aggression and monetary discounting functions for low (left) and high (right) aggression discounters from Studies 5-6.

\section{Suspicious Participants}

Three of our studies relied on deception (i.e., Studies 1-3). In each of these studies, some participants voiced suspicion regarding this deception. Specifically, 12 participants from Study 1 (4.22\% of the sample), 10 participants from Study 2 (3.80\%) and 3 participants from Study 3 $(1.33 \%)$ voiced suspicion regarding the existence of their ITAP opponent or chat partner(s), respectively. Suspicious participants were retained in all studies as their exclusion was not part of our preregistration plan and such suspicions are generally unrelated to participant behavior (Krasnow, Howard, \& Eisenbruch, 2019). However, to ensure that our findings were not artifacts of retaining these participants we reconducted each hypothesis test from these studies. The 
results of each (Supplemental Document 9) revealed no differences in our findings.

\section{General Discussion}

How do people decide whether to pursue some revenge now versus seeking more revenge later? According to a wealth of research people generally prefer immediate-but-lesser over delayed-but-greater rewards (Green \& Myerson, 2004). Laboratory studies indicate that people retaliate following provocation as a means of mood repair (Bushman, 2002; Chester \& DeWall, 2016) and that obtaining revenge is a rewarding experience (Chester, 2017). We synthesized these literatures to test the overarching hypothesis that people would temporally discount retaliatory aggression.

\section{Intertemporal Preferences for Revenge}

Across six studies, we found a remarkably strong preference for immediate-but-lesser over delayed-but-greater revenge. The ability of aggression to mirror such elements of decisionmaking observed in other rewards is consistent with the assertion that retaliation can be intrinsically rewarding (e.g., Chester, 2017). Examining whether our findings apply to other forms of aggression (e.g., intimate partner violence) may reveal that these intertemporal preferences are an important component of human belligerence.

\section{Situational and Dispositional Factors: Provocation, Antagonism, and Self-Control}

Provocation. In Studies 1-2 provocation led participants to more frequently choose to retaliate by selecting the aggression option they viewed as being more aversive. Study 3 demonstrated that aggression discounting is negatively associated with in-the-moment retaliation, as retaliatory aggression from the CPAT was linked to less discounting of future

revenge on the ACQ. Finally, Study 4 provided evidence that retaliation against a provoking person is subject to less discounting. Provoking experiences thus appear to be linked with less aggression discounting among those who find retaliation rewarding. 
Antagonistic Traits. Meta-analytic associations showed that those with greater antagonistic traits were more likely to be low discounters of aggression and thus hold greater preferences for delayed-but-greater revenge. Specifically, low aggression discounters exhibited greater levels of trait physical aggression. As is observed in other rewarding behaviors (e.g., exercise; Albelwi et al., 2019), the more frequently individuals engage in a behavior, the less likely they are to discount it. Our results support this assertion and its ability to generalize to aggressive behavior. Low aggression discounters also exhibited greater levels of trait physical sadism. This finding emphasizes the role of reward and pleasure in motivating a preference for delayed revenge (Chester \& DeWall, 2018). Finally, we found that trait angry rumination was also greater among low aggression discounters. This finding is consistent with a functional account of angry rumination, which posits that the tendency to ruminate over instigating experiences may have evolved for the purpose of facilitating greater revenge in the future (Denson, 2013). Thus, antagonistic traits may lead some to pass up immediate-but-lesser vengeance in service of inflicting more harm in the future.

Self-control. We observed a weak, positive meta-analytic association between trait selfcontrol and aggression discounting. As such, high aggression discounters also exhibited high trait self-control. However, it is unlikely that individuals with greater self-control chose the immediate option out of impulsivity. It may be the case that our observed meta-analytic association reflected overlap in the shared variance between trait self-control and agreeableness (i.e., low antagonism), and thus a desire to inflict less harm rather than an impulsive decisionmaking style (e.g., Jensen-Campbell et al., 2002). Conversely, results from Study 6 indicated that participants exhibited greater conflict when choosing delayed-but-greater revenge, which indicates the recruitment of some self-regulatory processes. The presence of greater conflict 
during such decisions supports a growing perspective in which (delayed) revenge is likely the result of greater deliberative self-regulation rather than simple impulses (Book, Volk, Holden, \& D’Agata, 2019; Lasko, Chester, Martelli, West, \& DeWall, 2019). Typically, self-control allows people to choose less severe aggression (e.g., Denson et al., 2012). Yet in our studies, participants were required to recruit greater self-control in order to choose the more severe aggression option. Accordingly, our predictions and our findings do not contradict previous work on self-control and aggression - they simply add a nuanced understanding thereof.

\section{Theoretical Implications}

The Patient Storm. An intertemporal framework of aggression can be well-couched within contemporary meta-theories of aggression. For instance, $\mathrm{I}^{3}$ meta-theory provides a comprehensive framework for the proximate causes of aggression and is supported by an evergrowing body of evidence (e.g., Finkel \& Hall, 2018). This framework posits that aggressive behavior is often caused by an interaction between three factors: instigation (e.g., provocation), impellance (e.g., antagonistic traits), and inhibition (e.g., trait self-control). Perfect Storm theory, which is derived from $\mathrm{I}^{3}$ meta-theory, predicts that aggression is most likely to occur and to be most severe under conditions of high instigation, high impellance, and low inhibition (e.g., Birkley \& Eckhardt, 2019). Our findings illuminate a possible variant of the Perfect Storm: the Patient Storm, wherein high inhibition is implemented in service of inflicting greater harm in the presence of high instigation and impellance.

General Theory of Crime. Our findings also hold implications for broader theories of antisocial behavior. The general theory of crime is a long-standing model that posits that deficits in self-control comprise a common bond among all criminal acts (Gottfredson \& Hirschi, 1990). In contrast, each of our studies evinced that more aggressive individuals are more likely to wait 
in service of inflicting greater harm against their target. Consistent with our findings, prior work indicates that such delay discounting is associated with impulsive, but not planful, criminal behaviors (Varghese, Charlton, Wood, \& Trower, 2014). It may be the case then that the impaired self-control central to the general theory of crime only accounts for impulsive or opportunistic crimes rather than a universal element of anti-social behavior.

\section{The Psychometric Properties of Aggression Discounting Measures}

Our inferences relied upon the validity and reliability of two measures that were constructed for this investigation: the Intertemporal Aggression Paradigm (ITAP) and Aggression Choice Questionnaire (ACQ). As evidence for their convergent validity, those who preferred delayed-but-greater revenge during the ITAP were likely to exhibit similar preferences during the ACQ. Preferences for delayed-but-greater revenge on both measures were also linked to greater dispositional physical aggression and physical sadism. As evidence of the ACQ's criterion validity, it was able to evoke decision conflict on choices in which the delayed reward was ultimately chosen, a behavioral hallmark of delay discounting tasks (Calluso, Committeri, Pezzulo, Lepora, \& Tosoni, 2015). Angry rumination was associated with discounting from the ACQ, but not the ITAP. This finding lends evidence to the ACQ's external validity, as those who ruminated over angering experiences more frequently discounted aggression less. Decision conflict exhibited during the ACQ was positively associated with conflict during the MCQ, indicating that intertemporal choices for both aggression and money engage similar cognitive processes. The ACQ also appeared to be reliable — capturing largely stable individual differences in intertemporal aggression preferences over several weeks. Despite this evidence, the validity of one of the tasks used as the basis for the ITAP (the Taylor Aggression Paradigm) has been debated by scholars. This debate is ongoing and has yielded evidence in favor of and 
against its external validity (e.g., Chester \& Lasko, 2019; Tedeschi \& Quigley, 1996). As such, we hope that these measures will be adopted by other investigators who can further estimate their validity and reliability.

\section{Divergence in Aggression Discounting}

Our cluster analyses revealed that participants fell into two broad categories of high and low aggression discounters. Such divergence in aggression discounting suggests that revenge is only rewarding for some individuals. Indeed, low aggression discounters demonstrated similar discounting functions for revenge and money whereas high aggression discounters demonstrated domain-specific functions. These findings are consistent with prior research indicating that individuals who find certain activities inherently rewarding (e.g., exercise, viewing pornography) discount them less (Albelwi et al., 2019; Lawyer, 2008), but stand at odds with the generalizability of the revenge-as-reward effect (e.g., Chester, 2017). Future research examining the revenge-as-reward effect should use the ACQ as a screening tool for recruitment or for quasiexperimental designs to further understand the psychological processes responsible for such differences in aggression discounting.

\section{Limitations and Future Directions}

The findings reported in the present work should be interpreted in the context of several limitations. First, our samples consisted only of undergraduate students. Though our participants were remarkably diverse in many ways (e.g., all study samples included a minority of white participants), we cannot speak to the generalizability of our results to populations characterized by more extreme violent and retributive tendencies. Similarly, we are unable to speak to the degree to which aggression discounting as operationalized in these studies may generalize to various forms of aggression. Future work is needed to examine the extent to which our findings 
generalize to clinical, forensic, and cross-cultural populations and to specific forms (e.g., verbal) of aggression. Second, approximately one-third of all participants selected the immediate option exclusively during the ACQ across Studies 2-6. In contrast, approximately one-seventh of participants selected the immediate option exclusively during the ITAP (see Supplemental Document 3, Table S8 for full details). This could be because provocation from the ITAP was immediately salient, whereas participants could have recalled a provoking event that occurred years prior for the ACQ. Future work should test how the temporal distance of provocation from an intertemporal choice of revenge may impact aggression discounting. Third, the necessarily contrived nature of the ITAP and hypothetical aspect of the ACQ were unlikely to have replicated the conditions in which intertemporal aggression decisions are made. Though monetary discounting measures show little difference between discounting rates for real or hypothetical rewards (Johnson \& Bickel, 2002) intertemporal revenge decisions are likely more complex. Similarly, the current data do not allow us to make claims about the external validity of the ITAP. As such, future work should focus on increasing the realism and examining the external validity of such aggression discounting measures. Finally, we only included three measures of antagonistic traits in the current work. Future work should examine the associations of other antagonistic traits (e.g., psychopathy) with rates of aggression discounting.

\section{Conclusions}

Human life often entails one provocation after the other. At a certain point, people decide that some antagonisms have crossed the line and are deserving of revenge. Yet how do people decide whether to seek some revenge now or bide their time and inflict more revenge later? Across six studies, we found that people treated such intertemporal decisions about revenge like they do for other rewards - they preferred receiving some now to receiving more later. In line 
with major theories of aggression, these preferences were readily shifted by experimental provocation and those with greater antagonistic traits were more willing to wait to deliver a more severe blow. Yet our results did not paint those who bided their time for greater revenge as impulsive, uninhibited individuals. Instead, they exhibited the recruitment of greater selfregulation. Embedded in this investigation is a crucial distinction — that all aggressive acts outside of the laboratory carry an inherent choice to aggress in the present or at a later time under more permissible circumstances. By integrating aggression research with an intertemporal framework, we hope to inspire other research into this area and how such an integration might advance our understanding of how people decide to hurt others in the present and the future. 


\section{References}

Albelwi, T. A., Rogers, R. D., \& Kubis, H. P. (2019). Exercise as a reward: Self-paced exercise perception and delay discounting in comparison with food and money. Physiology \& Behavior, 199, 333-342. https://10.1016/j.physbeh.2018.12.004

Anderson, C. A., \& Bushman, B. I. (2002). Human aggression. Annual Review of Psychology, 53, 27-51. https://doi.org/10.1146/annurev.psych.53.100901.135231

Anokhin, A. P., Grant, J. D., Mulligan, R. C., \& Heath, A. C. (2015). The genetics of impulsivity: evidence for the heritability of delay discounting. Biological Psychiatry, 77(10), 887-894. https://doi.org/10.1016/j.biopsych.2014.10.022

Barkley, R. A., Edwards, G., Laneri, M., Fletcher, K., \& Metevia, L. (2001). Executive functioning, temporal discounting, and sense of time in adolescents with attention deficit hyperactivity disorder (ADHD) and oppositional defiant disorder (ODD). Journal of Abnormal Child Psychology, 29(6), 541-556. https://doi.org/10.1023/A:1012233310098

Baumeister, R. F., DeWall, C. N., Ciarocco, N. J., \& Twenge, J. M. (2005). Social Exclusion Impairs Self-Regulation. Journal of Personality and Social Psychology, 88(4), 589-604. https://doi.org/10.1037/e501232006-005

Bench, S. W., \& Lench, H. C. (2019). Boredom as a seeking state: Boredom prompts the pursuit of novel (even negative) experiences. Emotion, 19(2), 242-254. https://doi.org/10.1037/emo0000433

Birkley, E. L., \& Eckhardt, C. I. (2019). Effects of instigation, anger, and emotion regulation on intimate partner aggression: Examination of "perfect storm" theory. Psychology of Violence, 9(2), 186-195. https://doi.org/10.1037/vio0000190

Boehm, C. (2011). Retaliatory violence in human prehistory. The British Journal of 
Criminology, 51(3), 518-534. https://doi.org/10.1093/bjc/azr020

Book, A., Visser, B. A., Volk, A., Holden, R. R., \& D'Agata, M. T. (2019). Ice and fire: Two paths to provoked aggression. Personality and Individual Differences, 138, 247-251. https://doi.org/10.1016/j.paid.2018.10.010

Buckels, E. E., \& Paulhus, D. L. (2014). Comprehensive Assessment of Sadistic Tendencies (CAST). Unpublished instrument, University of British Columbia, Vancouver, Canada.

Bushman, B. J. (2002). Does venting anger feed or extinguish the flame? Catharsis, rumination, distraction, anger, and aggressive responding. Personality and Social Psychology Bulletin, 28(6), 724-731. https://doi.org/10.1177/0146167202289002

Bushman, B. J., \& Baumeister, R. F. (1998). Threatened egotism, narcissism, self-esteem, and direct and displaced aggression: Does self-love or self-hate lead to violence? Journal of Personality and Social Psychology, 75(1), 219. https://doi.org/ 10.1037/00223514.75.1.219

Bushman, B. J., Baumeister, R. F., \& Phillips, C. M. (2001). Do people aggress to improve their mood? Catharsis beliefs, affect regulation opportunity, and aggressive responding. Journal of Personality and Social Psychology, 81(1), 17-32. https://doi.org/10.1037/0022-3514.81.1.17

Bushman, B. J., Bonacci, A. M., Pedersen, W. C., Vasquez, E. A., \& Miller, N. (2005). Chewing on it can chew you up: Effects of rumination on triggered displaced aggression. Journal of Personality and Social Psychology, 88, 969-983. https://doi.org/10.1037/00223514.88.6.969

Buss, A. H., \& Perry, M. (1992). The aggression questionnaire. Journal of Personality and Social Psychology, 63, 452-459. https://doi.org/10.1037/0022-3514.63.3.452 
Calluso, C., Committeri, G., Pezzulo, G., Lepora, N., \& Tosoni, A. (2015). Analysis of hand kinematics reveals inter-individual differences in intertemporal decision dynamics. Experimental Brain Research, 233(12), 3597-3611. https://doi.org/ 10.1007/s00221-0154427-1

Cherek, D. R., Moeller, F. G., Dougherty, D. M., \& Rhoades, H. (1997). Studies of violent and nonviolent male parolees: II. Laboratory and psychometric measurements of impulsivity. Biological Psychiatry, 41(5), 523-529. https://doi.org/10.1016/S00063223(96)00426-X

Chester, D. S. (2017). The role of positive affect in aggression. Current Directions in Psychological Science, 26(4), 366-370. https://doi.org/10.1177/0963721417700457

Chester, D. S., \& DeWall, C. N. (2018). Personality correlates of revenge- seeking: Multidimensional links to physical aggression, impulsivity, and aggressive pleasure. Aggressive Behavior, 44(3), 235-245. https://doi.org/10.1002/ab.21746

Chester, D. S., \& DeWall, C. N. (2017). Combating the sting of rejection with the pleasure of revenge: A new look at how emotion shapes aggression. Journal of Personality and Social Psychology, 112(3), 413. https://doi.org/10.1037/pspi0000080

Chester, D. S. \& DeWall, C. N. (2016). The pleasure of revenge: Retaliatory aggression arises from a neural imbalance toward reward. Social Cognitive and Affective Neuroscience, 11(7), 1173-1182. https://doi.org/10.1093/scan/nsv082

Chester, D. S., \& Lasko, E. N. (2019). Validating a standardized approach to the Taylor Aggression Paradigm. Social Psychological and Personality Science, 10(5), 620-631. https://doi.org/10.1177/1948550618775408

Chester, D. S., DeWall, C. N., \& Enjaian, B. (2019b). Sadism and aggressive behavior: Inflicting 
pain to feel pleasure. Personality and Social Psychology Bulletin, 45(8), 1252-1268. https://doi.org/10.1177/0146167218816327

Chester, D. S., Lynam, D. R., Milich, R., \& DeWall, C. N. (2018). Neural mechanisms of the rejection-aggression link. Social Cognitive and Affective Neuroscience, 13(5), 501-512. https://doi.org/10.1093/scan/nsy025

Chester, D. S., Lynam, D. R., Milich, R. \& DeWall, C. N. (2017). Physical aggressiveness and gray matter deficits in ventromedial prefrontal cortex. Cortex, 97, 17-22. https://doi.org/10.1016/j.cortex.2017.09.024

Chester, D. S., Bell, S. B., DeWall, C. N., West, S. J., Romero- Lopez, M., \& Craig, A. W. (2019a). Neural correlates of intertemporal choice in aggressive behavior. Aggressive Behavior, 45, 507-516. https://doi.org/10.1002/ab.21838

Denson, T. F. (2013). The multiple systems model of angry rumination. Personality and Social Psychology Review, 17(2), 103-123. https://doi.org/10.1177/1088868312467086

Denson, T. F., DeWall, C. N., \& Finkel, E. J. (2012). Self-control and aggression. Current Directions in Psychological Science, 21(1), 20-25. https://doi.org/10.1177/0963721411429451

Denson, T. F., Pedersen, W. C., Friese, M., Hahm, A., \& Roberts, L. (2011). Understanding impulsive aggression: Angry rumination and reduced self-control capacity are mechanisms underlying the provocation-aggression relationship. Personality and Social Psychology Bulletin, 37(6), 850-862. https://doi.org/10.1177/0146167211401420

Donate, A. P. G., Marques, L. M., Lapenta, O. M., Asthana, M. K., Amodio, D., \& Boggio, P. S. (2017). Ostracism via virtual chat room: Effects on basic needs, anger and pain. PloS one, 12(9), e0184215. https://doi.org/10.1371/journal.pone.0184215 
Dougherty, D. M., Bjork, J. M., Huckabee, H. C., Moeller, F. G., \& Swann, A. C. (1999). Laboratory measures of aggression and impulsivity in women with borderline personality disorder. Psychiatry Research, 85(3), 315-326. https://doi.org/10.1016/S01651781(99)00011-6

Elbert, T., Schauer, M., \& Moran, J. K. (2018). Two pedals drive the bi-cycle of violence: reactive and appetitive aggression. Current Opinion in Psychology, 19, 135-138. https://doi.org/10.1016/j.copsyc.2017.03.016

Finkel, E. J., \& Hall, A. N. (2018). The $\mathrm{I}^{3}$ Model: A metatheoretical framework for understanding aggression. Current Opinion in Psychology, 19, 125-130. https://doi.org/10.1016/j.copsyc.2017.03.013

Finkel, E. J., DeWall, C. N., Slotter, E. B., Oaten, M., \& Foshee, V. A. (2009). Self-regulatory failure and intimate partner violence perpetration. Journal of Personality and Social Psychology, 97(3), 483-499. https://doi.org/10.1037/a0015433

Freeman J.B., Ambady, N. (2010). MouseTracker: software for studying real time mental processing using a computer mouse-tracking method. Behavioral Research Methods, 42, 226-241. https://doi.org/10.3758/BRM.42.1.226

Frost, R., \& McNaughton, N. (2017). The neural basis of delay discounting: A review and preliminary model. Neuroscience \& Biobehavioral Reviews, 79, 48-65. https://doi.org/10.1016/j.neubiorev.2017.04.022

Friedel, J. E., DeHart, W. B., Madden, G. J., \& Odum, A. L. (2014). Impulsivity and cigarette smoking: Discounting of monetary and consumable outcomes in current and nonsmokers. Psychopharmacology, 231(23), 4517-4526. https://doi.org/10.1007/s00213-014$3597-\mathrm{Z}$ 
Frye, C. C., Galizio, A., Friedel, J. E., DeHart, W. B., \& Odum, A. L. (2016). Measuring delay discounting in humans using an adjusting amount task. Journal of Visualized Experiments, 107, e53584. https://doi.org/10.3791/53584

Gillebaart, M., Schneider, I. K., \& De Ridder, D. T. (2016). Effects of trait self- control on response conflict about healthy and unhealthy food. Journal of Personality, 84(6), 789798. https://doi.org/10.1111/jopy.12219

Gollwitzer, M., \& Bushman, B. J. (2012). Do victims of injustice punish to improve their mood?. Social Psychological and Personality Science, 3(5), 572-580. https://doi.org/10.1177/1948550611430552

Green, L., \& Myerson, J. (2004). A discounting framework for choice with delayed and probabilistic rewards. Psychological Bulletin, 130(5), 769-792. https://doi.org/10.1037/0033-2909.130.5.769

Green, L., Fry, A. F., \& Myerson, J. (1994). Discounting of delayed rewards: A life-span comparison. Psychological Science, 5(1), 33-36. https://doi.org/10.1111/j.14679280.1994.tb00610.x

Gupta, A., Datta, S., \& Das, S. (2018). Fast automatic estimation of the number of clusters from the minimum inter-center distance for k-means clustering. Pattern Recognition Letters, 116, 72-79. https://doi.org/10.1016/j.patrec.2018.09.003

Hartigan, J. A., \& Wong, M. A. (1979). Algorithm AS 136: A k-means clustering algorithm. Applied Statistics, 28, 100-108. https://doi.org/10.2307/2346830

Houston, D. A., \& Doan, K. (1996). Comparison of paired choice alternatives and choice conflict. Applied Cognitive Psychology, 10(7), 125-135. https://doi.org/ 10.1002/(SICI)1099-0720(199611)10:7<125::AID-ACP432>3.0.CO;2-2 
Johnson, M. W., \& Bickel, W. K. (2002). Within- subject comparison of real and hypothetical money rewards in delay discounting. Journal of the Experimental Analysis of Behavior, 77(2), 129-146. https://doi.org/10.1901/jeab.2002.77-129

Kaplan, B. A., Amlung, M., Reed, D. D., Jarmolowicz, D. P., McKerchar, T. L., \& Lemley, S. M. (2016). Automating scoring of delay discounting for the 21-and 27-item monetary choice questionnaires. The Behavior Analyst, 39(2), 293-304. https://doi.org/10.1007/s40614-016-0070-9

Keatley, D. A., Allom, V., \& Mullan, B. (2017). The effects of implicit and explicit self-control on self-reported aggression. Personality and Individual Differences, 107, 154-158. https://doi.org/10.1016/j.paid.2016.11.046

Kirby, K. N. (2009). One-year temporal stability of delay-discount rates. Psychonomic Bulletin \& Review, 16(3), 457-462. https://doi.org/10.3758/PBR.16.3.457

Kirby, K. N., Petry, N. M., \& Bickel, W. K. (1999). Heroin addicts have higher discount rates for delayed rewards than non-drug-using controls. Journal of Experimental Psychology: General, 128, 78-87. https://doi.org/10.1037/0096-3445.128.1.78

Kirby, K. N., Winston, G. C., \& Santiesteban, M. (2005). Impatience and grades: Delay-discount rates correlate negatively with college GPA. Learning and Individual Differences, 15(3), 213-222. https://doi.org/10.1016/j.lindif.2005.01.003

Koepfler, J., Brewstwer, J., Stoloff, M., \& Saville, B. (2012). Predicting police aggression: Comparing traditional and non-traditional prediction models. Journal of Police and Criminal Psychology, 27(2), 141-149. https://doi.org/10.1007/s11896-012-9101-y

Krasnow, M. M., Howard, R. M. \& Eisenbruch, A. B. (2019). The importance of being honest? Evidence that deception may not pollute social science subject pools after all. Behavioral 
Research Methods, 52, 1175-1188. https://doi.org/10.3758/s13428-019-01309-y

Lasko, E. N., Chester, D. S., Martelli, A. M., West, S. J., \& DeWall, C. N. (2019). An investigation of the relationship between psychopathy and greater gray matter density in lateral prefrontal cortex. Personality Neuroscience, 2, 1-10. https://doi.org/10.1017/pen.2019.8

Lawrence, C., \& Hutchinson, L. (2013). The influence of individual differences in sensitivity to provocations on provoked aggression. Aggressive Behavior, 39(3), 212-221. https://doi.org/10.1002/ab.21473

Lawyer, S. R. (2008). Probability and delay discounting of erotic stimuli. Behavioural Processes, 79(1), 36-42. https://doi.org/10.1016/j.beproc.2008.04.009

Lin, H., \& Epstein, L. H. (2014). Living in the moment: Effects of time perspective and emotional valence of episodic thinking on delay discounting. Behavioral Neuroscience, 128(1), 12. https://doi.org/10.1037/a0035705

McCullough, M. E., Kurzban, R., \& Tabak, B. A. (2013). Cognitive systems for revenge and forgiveness. Behavioral and Brain Sciences, 36(1), 1-15. https://doi.org/10.1017/S0140525X11002160

Mischel, W., Grusec, J., \& Masters, J. C. (1969). Effects of expected delay time on the subjective value of rewards and punishments. Journal of Personality and Social Psychology, 11(4), 363-373. https://doi.org/10.1037/h0027265

Mishra, S., \& Lalumière, M. L. (2017). Associations between delay discounting and risk- related behaviors, traits, attitudes, and outcomes. Journal of Behavioral Decision Making, 30(3), 769-781. https://doi.org/10.1002/bdm.2000

Myerson, J., Green, L., \& Warusawitharana, M. (2001). Area under the curve as a measure of 
discounting. Journal of the Experimental Analysis of Behavior, 76(2), 235-243. https://doi.org/10.1901/jeab.2001.76-235

Odum, A. L. (2011). Delay discounting: Trait variable? Behavioural Processes, 87(1), 1-9. https://doi.org/10.1016/j.beproc.2011.02.007

Peck, S., \& Byrne, T. (2019). Free-operant discounting: Initial results from an adjusting-duration procedure. Behavior Analysis: Research and Practice, 19(3), 292. https://doi.org/10.1037/bar0000146

Pfattheicher, S., Lazarević, L. B., Westgate, E. C., \& Schindler, S. (2020). On the relation of boredom and sadistic aggression. Journal of Personality and Social Psychology. Advance online publication. https://doi.org/10.1037/pspi0000335

R Core Team (2020). R: A language and environment for statistical computing. $R$ Foundation for Statistical Computing, Vienna, Austria. https://www.R-project.org/

Richard, F. D., Bond Jr, C. F., \& Stokes-Zoota, J. J. (2003). One hundred years of social psychology quantitatively described. Review of General Psychology, 7, 331-363. https://doi.org/10.1037/1089-2680.7.4.331

Sousa, T., \& Neves, P. (2020). Two tales of rumination and burnout: Examining the effects of boredom and overload. Applied Psychology: An International Review. Advance online publication. 1-27. https://doi.org/10.1111/apps.12257

Sukhodolsky, D. G., Golub, A., \& Cromwell, E. N. (2001). Development and validation of the anger rumination scale. Personality and Individual Differences, 31(5), 689-700. https://doi.org/10.1016/S0191-8869(00)00171-9

Tangney, J. P., Baumeister, R. F., \& Boone, A. L. (2004). High self- control predicts good adjustment, less pathology, better grades, and interpersonal success. Journal of 
Personality, 72(2), 271-324. https://doi.org/10.1111/j.0022-3506.2004.00263.x

Taylor, S. P. (1967). Aggressive behavior and physiological arousal as a function of provocation and the tendency to inhibit aggression. Journal of Personality, 35(2), 297-310. https://doi.org/10.1111/j.1467-6494.1967.tb01430.x

Tedeschi, J. T., \& Quigley, B. M. (1996). Limitations of laboratory paradigms for studying aggression. Aggression and Violent Behavior, 1(2), 163-177. https://doi.org/10.1016/1359-1789(95)00014-3

The jamovi project (2020). jamovi v 1.2.2 [Computer Software]. Retrieved from https://www.jamovi.org

van Tilburg, W. A. P., \& Igou, E. R. (2017). Boredom begs to differ: Differentiation from other negative emotions. Emotion, 17(2), 309-322. https://doi.org/10.1037/emo0000233

Varghese, F. P., Charlton, S. R., Wood, M., \& Trower, E. (2014). Temporal discounting and criminal thinking: Understanding cognitive processes to align services. Psychological Services, 11(2), 171-178. https://doi.org/10.1037/a0035004

Verduyn, P., \& Lavrijsen, S. (2015). Which emotions last longest and why: The role of event importance and rumination. Motivation and Emotion, 39(1), 119-127. https://doi.org/10.1007/s11031-014-9445-y

Webster, G. D., DeWall, C. N., Pond Jr, R. S., Deckman, T., Jonason, P. K., Le, B. M., ... \& Smith, C. V. (2014). The brief aggression questionnaire: Psychometric and behavioral evidence for an efficient measure of trait aggression. Aggressive Behavior, 40(2), 120139. https://doi.org/10.1002/ab.21507

West, S. J., Hyatt, C. S., Miller, J. D., \& Chester, D. S. (2021). p- Curve analysis of the Taylor Aggression Paradigm: Estimating evidentiary value and statistical power across 50 years 
of research. Aggressive Behavior, 47(2), 183-193. https://doi.org/10.1002/ab.21937

White, S. F., Clanton, R., Brislin, S. J., Meffert, H., Hwang, S., Sinclair, S., \& Blair, R. J. R. (2014). Reward: Empirical contribution: Temporal discounting and conduct disorder in adolescents. Journal of Personality Disorders, 28(1), 5-18.

https://doi.org/10.1521/pedi.2014.28.1.5 


\section{Appendix A}

\section{Aggression Choice Questionnaire}

Please take a moment and think about a person who has really hurt you and you feel a great amount of anger towards. If you cannot think of a specific person, imagine a fake person who has really hurt you and you feel a great amount of anger towards.

Once you have done this, please indicate how much pain and suffering that you would like to inflict on this person in each of the following questions, using the scale below as a reference. Keep in mind that 'pain' is multifaceted and can involve physical, verbal, societal, or social aspects.

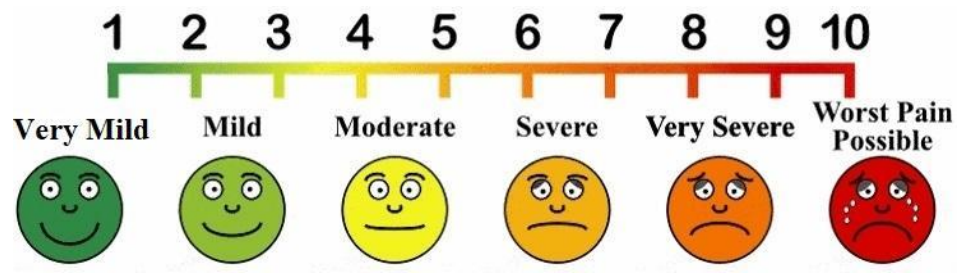

Would you like to...

1. Inflict pain level 7 right now or inflict pain level 9 in 74 days?

2. Inflict pain level 3 right now or inflict pain level 8 in 12 days?

3. Inflict pain level 1 right now or inflict pain level 3 in 14 days?

4. Inflict pain level 3 right now or inflict pain level 8 in 7 hours?

5. Inflict pain level 6 right now or inflict pain level 10 in 16 hours?

6. Inflict pain level 2 right now or inflict pain level 9 in 1 year?

7. Inflict pain level 9 right now or inflict pain level 10 in 1 hour?

8. Inflict pain level 2 right now or inflict pain level 9 in 35 hours?

9. Inflict pain level 4 right now or inflict pain level 8 in 260 days?

10. Inflict pain level 2 right now or inflict pain level 5 in 10 days?

11. Inflict pain level 4 right now or inflict pain level 7 in 3 hours?

12. Inflict pain level 3 right now or inflict pain level 6 in 42 days?

13. Inflict pain level 9 right now or inflict pain level 10 in 29 days?

14. Inflict pain level 7 right now or inflict pain level 9 in 7 hours?

15. Inflict pain level 3 right now or inflict pain level 5 in 11 days?

16. Inflict pain level 1 right now or inflict pain level 4 in 50 days?

17. Inflict pain level 1 right now or inflict pain level 10 in 938 days?

18. Inflict pain level 5 right now or inflict pain level 8 in 38 hours?

19. Inflict pain level 5 right now or inflict pain level 10 in 10 hours?

20. Inflict pain level 7 right now or inflict pain level 10 in 45 days?

21. Inflict pain level 3 right now or inflict pain level 7 in 3 days?

22. Inflict pain level 3 right now or inflict pain level 4 in 6 days?

23. Inflict pain level 8 right now or inflict pain level 10 in 6 hours?

24. Inflict pain level 6 right now or inflict pain level 8 in 14 days?

25. Inflict pain level 4 right now or inflict pain level 6 in 31 hours?

26. Inflict pain level 4 right now or inflict pain level 7 in 31 days?

27. Inflict pain level 5 right now or inflict pain level 6 in 1 hour? 